\title{
Lysosome targeting chimeras (LYTACs) that engage a liver-specific asialoglycoprotein receptor for targeted protein degradation
}

\author{
Green Ahn ${ }^{1}$, Steven M. Banik ${ }^{1}$, Caitlyn L. Miller ${ }^{2}$, Nicholas M. Riley ${ }^{1}$, Jennifer R. Cochran², \\ Carolyn R. Bertozzi ${ }^{1,3 \dagger}$ \\ ${ }^{1}$ Department of Chemistry, Stanford University, Stanford, California 94305, USA. \\ ${ }^{2}$ Department of Bioengineering, Stanford University, Stanford, California 94305, USA. \\ ${ }^{3}$ Howard Hughes Medical Institute, Stanford, California 94305, USA. \\ ${ }^{\dagger}$ All correspondence should be addressed to bertozzi@stanford.edu
}

\begin{abstract}
Selective protein degradation platforms have afforded new development opportunities for therapeutics and tools for biological inquiry. The first lysosome targeting chimeras (LYTACs) targeted extracellular and membrane proteins for degradation by bridging a target protein to an endogenous lysosome targeting receptor, the cation-independent mannose-6-phosphate receptor (Cl-M6PR). Here we developed LYTACs that engage the asialoglycoprotein receptor (ASGPR), a liver-specific lysosomal targeting receptor, to degrade membrane proteins in a tissuespecific manner. We conjugated antibody-based binders targeting cell-surface proteins to a triGalNAc motif that engages ASGPR. The resulting LYTACs directed lysosome trafficking of the bound targets and subsequent degradation. Degradation mediated by an EGFR-targeted GaINAC-LYTAC resulted in significant functional effects on the downstream kinase signaling of EGFR compared to canonical inhibition with a monoclonal antibody. Furthermore, we demonstrated that a small target binder, a $3.4 \mathrm{kDa}$ peptide, can be linked to a single tri-GalNAc ligand to degrade integrins and significantly reduce cell proliferation. Site-specific chemical conjugation of one or two tri-GalNAc ligands to antibody scaffolds improved the pharmacokinetic profile of GalNAc-LYTACs in vivo compared to non-specific chemical conjugation. GalNAcLYTACs represent an exciting new paradigm for cell-type restricted degradation of proteins.
\end{abstract}

\section{Introduction}

Targeted protein degradation (TPD) is a promising new therapeutic modality and a tool for probing biological pathways as well as the cellular degradation machinery. Most TPD platforms such as $\mathrm{IMiDs}^{1,2}$, proteolysis targeting chimeras (PROTACs) ${ }^{3,4}$, dTAGs ${ }^{5,6}$, Trim-Away ${ }^{7}$, and SNIPERs ${ }^{8}$, rely on the ubiquitin proteasome system (UPS). Recently, AUTACs ${ }^{9}$ and ATTECs ${ }^{10,11}$ have emerged as approaches that exploit the intracellular autophagy machinery for mediating TPD. Advances in TPD strategies have accelerated over the past two decades, and PROTACs have recently entered clinical trials ${ }^{12}$. However, the cytosolic localization of the UPS and targetable autophagy machinery restricts these approaches to proteins with cytosolic domains and requires degraders to be cell-permeable. In order to relax these constraints and expand the scope of TPD to extracellular targets, our lab has developed lysosome targeting chimeras (LYTACs) which bind and direct plasma membrane-associated or secreted proteins to lysosomes ${ }^{13}$. First-generation LYTACs employed the cation-independent mannose-6-phosphate receptor (Cl-M6PR) that endogenously traffics hydrolases and other cargo to the lysosome ${ }^{14}$. LYTACs were composed of a target binding moiety (e.g. antibody or small molecule) linked to a Cl-M6PR binding ligand, mannose-6-phosphonate (M6Pn). These M6Pn-LYTACs promoted lysosomal degradation of disease-relevant extracellular and membrane proteins by bridging the target protein with $\mathrm{Cl}-\mathrm{M} 6 \mathrm{PR}$.

$\mathrm{Cl}-\mathrm{M} 6 \mathrm{PR}$ is one of several lysosome trafficking receptors that could, in principle, be harnessed for the design of LYTACs. Indeed, whereas Cl-M6PR is broadly expressed in most tissues, other lysosome trafficking receptors have tissue-specific expression patterns. Such receptors offer the opportunity to achieve tissue-specific LYTAC activity. For therapeutic 
development, the ability to select in which tissue degradation occurs could have benefits for the therapeutic window.

Here, we develop LYTACs that engage the liver-specific asialoglycoprotein receptor $(A S G P R)^{20}$ as a lysosome targeting receptor (Fig. 1a). ASGPR recognizes glycoproteins bearing $\mathrm{N}$-acetylgalactosamine (GalNAc) or galactose (Gal) ligands and internalizes them via clathrinmediated endocytosis ${ }^{15,16}$. Following internalization and endosomal acidification, ASGPR releases GalNAc or Gal and recycles back to the plasma membrane, while glycoproteins proceed to the lysosome ${ }^{17}$. ASGPR has been exploited to achieve efficient delivery of various cargo to the liver, most notably, siRNA and ASO therapeutics ${ }^{18-22}$. We developed LYTACs comprising an antibody against a target of interest conjugated to homogeneous GalNAc ligands that induce targeted, cell type-specific degradation. In doing so, we demonstrated that receptor-mediated degradation is generalizable beyond Cl-M6PR. Additionally, we showed that a $3.4 \mathrm{kDa}$ peptide, a much smaller binder than an antibody, can be linked to a single tri-GalNAc ligand to degrade integrins resulting in anti-proliferative effects in hepatocellular carcinoma (HCC) cells. We then simplified the structural architecture of antibody-based GalNAc-LYTACs through site-specific conjugation, which enabled modulation of the pharmacokinetic profile of GalNAc-LYTACs.

\section{Results}

\section{Construction of GalNAc-LYTACs and internalization in HEPG2 cells}

Prior work on siRNA therapeutics revealed that triantenerrary GalNAc (tri-GalNac) ligands engage ASGPR with low nanomolar affinity ${ }^{23,24,25}$ and showed promising efficacy and safety profiles $^{26,27}$. The homogeneous nature of a triGalNAc ligand was additionally appealing as it would enable precise characterization of ligand to antibody ratios, which was challenging with the heterogenous polymers utilized in the initial M6Pn-LYTACs. Therefore, we synthesized triGalNAc-DBCO in 8 steps from peracetylated GalNAc and a Cbz-protected dendrimer scaffold ${ }^{28,21}$ (Fig. 1b). Tri-GalNAc-DBCO was conjugated to azides on non-specifically labeled antibodies via Cu-free strain-promoted azide-alkyne cycloaddition (Extended Data Fig. 1). The conjugation reaction was monitored by native gel electrophoresis, as the GalNAc conjugated antibody migrates slower than the azide functionalized starting material as a result of increased hydrodynamic size (Fig. 1c). To confirm that antibody-GalNAc conjugates can trigger internalization of extracellular targets via ASGPR, we examined LYTAC-mediated uptake in an HCC cell line, HEPG2. We included the first-generation LYTAC (M6Pn-LYTAC) ${ }^{29}$ that engages the Cl-M6PR as a comparison. HEPG2 cells were incubated with anti-rabbit lgG-647 and goatanti-rabbit (control), goat-anti-rabbit M6Pn (M6Pn-LYTAC), or goat-anti-rabbit GalNAc (GalNAcLYTAC) for 1 hour, then intracellular fluorescence was analyzed by flow cytometry (Fig. 1d). M6Pn-LYTAC increased cellular fluorescence 2-fold relative to the control while GalNAc-LYTAC increased 16-fold relative to the control (Fig. 1e). This result was confirmed by confocal microscopy, where GalNAc-LYTAC treatment resulted in high IgG-647 signal that co-localized with Lysotracker, indicating that GalNAc-LYTACs traffic to the acidic compartments in cells (Fig. 1f). The superior internalizing efficiency of GalNAc-LYTAC compared to M6Pn-LYTAC is potentially due to the higher surface expression of ASGPR versus CI-M6PR in hepatocytes (Extended Data Fig. 2).

\section{Degradation of EGFR via GaINAC-LYTAC}

We next asked if GalNAc-LYTACs could mediate degradation of membrane proteins in HCC cell lines. We chose epidermal growth factor receptor (EGFR) as a target as it is overexpressed in HCC patients and its dysregulated activity has been implicated in primary resistance to sorafenib, the standard of care for advanced $\mathrm{HCC}^{30,31}$. Moreover, as EGFR was previously targeted with our first-generation M6Pn-LYTACs, we sought to compare GalNAcLYTACs with earlier congeners. Cetuximab (Ctx) is an FDA-approved blocking antibody against EGFR for colorectal and head and neck cancer ${ }^{32,33}$. We conjugated Ctx to the tri-GalNAc ligand 
(Fig. 2a), and MALDI-MS analysis of the product (Ctx-GalNAc) revealed an average of 10.5 triGalNAc residues per antibody (Extended Data Fig. 3). We treated HEP3B cells with Ctx-GalNAc, then measured surface levels of EGFR by flow cytometry using an orthogonal detection antibody. Ctx-GalNAc degraded $>70 \%$ of cell surface EGFR in HEP3B cells, a level similar to the M6PnLYTACs (Fig. 2b).

We then evaluated the depletion of total EGFR in HEP3B, HEPG2, and HUH7 HCC cell lines. We observed $>70 \%$ total degradation with Ctx-GalNAc in HEP3B, consistent with the observations from cell-surface degradation. HEPG2 and HUH7 cells also exhibited comparable degradation efficiency (Fig. 2c). Degradation was found to depend on concentration, as CtxGalNAc mediated $50 \%$ degradation of cell-surface EGFR in HEP3B cells at a concentration as low as $1 \mathrm{nM}$. Maximum degradation was reached at concentration of $10 \mathrm{nM}$ and this degree of degradation persisted at higher concentrations, indicating that these LYTACs do not display the "hook-effect" within this concentration regime that has been observed with other bifunctional molecules $^{34}$ (Fig. 2d). Ctx-GalNAc mediated degradation of cell-surface EGFR over 48 hours, reaching $>50 \%$ degradation at 24 hours (Fig. 2e, Extended Data Fig. 4). Visualization and quantification of EGFR by confocal microscopy following LYTAC treatment showed diminished membrane EGFR signals, consistent with the observations from flow cytometry and western blot (Fig. 2f, Extended Data Fig. 5). Through several measurements, we showed that GalNAc-LYTACs perform comparably to M6Pn-LYTACs, demonstrating the potential generality of lysosome targeting receptor-mediated degradation mechanism and extending the internalizing ligand set to scalable, homogeneous structures.

\section{Mechanism of ASGPR-mediated degradation}

To confirm that depletion of EGFR by Ctx-GalNAc was dependent on ASGPR, HEP3B cells were treated with siRNA targeting ASGPR. Degradation via the Ctx-GalNAc LYTAC was completely abolished following ASGPR knockdown, while EGFR degradation proceeded in cells transfected with non-targeting siRNA. Furthermore, Ctx-GalNAc treatment did not alter ASGPR levels in these cells (Fig. 3a, Extended Data Fig. 6). Treatment with bafilomycin A1 or chloroquine ablated EGFR degradation mediated by Ctx-GalNAc, confirming that the degradation mechanism promoted by GalNAc-LYTACs depends on a functional endocytic pathway (Fig. 3b).

\section{Functional effect following GaINAC-LYTAC mediated degradation}

Next, we sought to determine whether degradation of EGFR would impact downstream kinase signaling compared to treatment with Ctx alone. Following LYTAC treatment, HEP3B cells were stimulated with $100 \mathrm{ng} / \mathrm{ml}$ or $50 \mathrm{ng} / \mathrm{ml}$ of EGF for 1 hour to activate downstream kinase phosphorylation. After EGF stimulation, levels of phosphorylated EGFR (pEGFR), Akt (pAkt), and MAPK (pERK1/2) were reduced upon Ctx-GalNAc or Ctx-M6Pn treatment compared to Ctx. Stimulation with lower concentrations of EGF resulted in greater relative reductions in phosphorylated EGFR and of phosphorylated Akt and ERK1/2 by both LYTACs compared to Ctx (Fig. 3c). These results highlight that LYTAC-driven degradation can exert more profound effects on downstream signaling compared to blocking of EGFR by Ctx alone.

Given that LYTACs mediate trafficking of membrane proteins to lysosomes, we asked if GalNAc-LYTACs affect lysosomal health in cells. Untreated cells and cells treated with CtxGalNAc exhibited a similar number of lysosomes upon staining with Lysotracker, while staining intensity was reduced in cells treated with LLOMe, a lysosomal damaging reagent (Extended Data Fig. 7a). Untreated cells and Ctx-GalNAc treated cells exhibited greater Cathepsin B activity compared to LLOMe treated cells. Although per cell quantitation showed that Ctx-GalNAc treatment resulted in reduction of Cathepsin B activity compared to untreated cells, activities were higher than that of Ctx treated cells and significantly higher than LLOMe treated cells (Extended Data Fig. 7b). We also examined the expression levels of ALIX, a marker for lysosomal membrane damage repair. While ALIX levels were increased in LLOMe treated cells, untreated and Ctx- 
GalNAc treated cells exhibited significantly reduced ALIX staining (Extended Data Fig. 7c). Taken together, treatment with Ctx-GalNAc resulted in greater lysosomal health compared to Ctx and similar health to untreated cells.

\section{GaINAC-LYTAC enables cell-specific degradation}

The exclusive expression of ASGPR on hepatocytes should enable selective degradation of membrane proteins on liver cells. To test this hypothesis, we co-cultured HEP3B (ASGPR ${ }^{+}$, $\mathrm{EGFR}^{+}, \mathrm{M} \mathrm{PR}{ }^{+}$) and HeLa-GFP $\left(\mathrm{ASGPR}^{-}, \mathrm{EGFR}^{+}, \mathrm{M} \mathrm{PR}^{+}\right)$and treated the co-culture with Ctx conjugates and analyzed EGFR degradation in each cell-type by flow cytometry (Fig. 4a). CtxGalNAc selectively ablated cell-surface EGFR from HEP3B cells, while HeLa-GFP maintained high EGFR expression. In contrast, Ctx-M6Pn degraded EGFR in both cell types as CI-M6PR is expressed in both HEP3B and HeLa-GFP (Fig. 4b). These data support the hypothesis that harnessing a recycling receptor with restricted expression enables LYTACs to degrade proteins in a cell-specific manner.

\section{GaINAc-LYTACs can target HER2}

To examine the ability of ASGPR-directed LYTACs to degrade additional membrane targets, we developed a LYTAC targeting HER2. HER2 may regulate tumor progression in early stage HCC patients by inducing epithelial-mesenchymal transition, and can be upregulated in $\mathrm{HCC}^{35}$. Briefly, pertuzumab (Ptz), an approved HER2 antibody for HER2-positive breast cancer, was conjugated to the tri-GalNAc ligand, and MALDI-MS analysis confirmed that Ptz had been labeled with 11 tri-GalNAc moieties (Ptz-GalNAc) (Extended Data Fig. 8). Ptz-GalNAc reduced $76 \%$ of total HER2 in HEPG2 cells, while Ptz alone degraded only $38 \%$ (Fig. 5a). Visualization by confocal microscopy revealed stark reduction and relocalization of HER2 signal in HEPG2 cells treated with Ptz-GalNAc compared to the cells treated with unmodified Ptz (Fig. 5b). Strikingly, 2hour treatment with Ptz-GalNAc resulted in a punctate localization pattern of HER2 by confocal microscopy (Extended Data Fig. 9a). These puncta did not co-localize with early endosome antigen 1 (EEA1), suggesting that HER2 may be trapped in other endocytic vesicles within 2 hours of treatment. Treatment with Ptz-M6Pn for 2 hours showed membrane-localized HER2 and did not indicate similar internalization. After 48 hours, treatment with Ptz-M6Pn also induced reduction and relocalization of HER2 signal (Extended Data Fig. 9b) These results suggest that there is a kinetic difference in the internalization mediated by M6Pn- and GalNAc-LYTACs, and that Ptz-GalNAc can remove membrane HER2 within 2 hours.

\section{Peptide-based GaINAC-LYTACs degrade integrins and induce anti-proliferative effect.}

Prior LYTACs targeting membrane proteins were based on antibody or antibody fragments as the target binders. Although antigen-binding fragments (Fab) non-specifically conjugated to several M6Pn polymers could induce receptor degradation ${ }^{29}$, we wondered if a small, synthetic peptide binder containing a single ASGPR ligand can promote degradation and induce enhanced functional consequences. To test this hypothesis, we used a targeting ligand composed of a polyspecific integrin-binding peptide (PIP), also known as EETI 2.5F, that was previously engineered to bind several tumor-associated integrins with high affinity ${ }^{36}$. In particular, PIP binds to $\alpha_{v} \beta_{1}, \alpha_{v} \beta_{3}, \alpha_{v} \beta_{5}, \alpha_{v} \beta_{6}$, and $\alpha_{5} \beta_{1}$ integrins, which are known to be overexpressed on various cancer types and facilitate proliferation, migration, and metastasis ${ }^{37}$. Given that the $3.4 \mathrm{kDa}$ PIP peptide is produced by solid phase peptide synthesis ${ }^{38}$, we readily incorporated azido-L-norvaline into the sequence to enable site-specific conjugation via a single tri-GalNAc-DBCO moiety, resulting in PIP-GalNAc (Fig. 5c, Extended Data Fig. 10).

We measured the surface levels of integrins by flow cytometry following treatment in HEPG2 cells, and observed that PIP-GaINAc depleted cell-surface $\alpha_{v} \beta_{3}$ integrin 3-fold relative to PIP treatment alone. Treatment with PIP increased expression of integrin $\alpha_{v} \beta_{5}$, while PIP- 
GalNAc overturned this effect resulting in modest degradation. Measurement of additional integrins that interact with PIP was challenging due to their low surface expression or a lack of specific detection antibody. Nevertheless, we determined the total surface level of integrins that bind to PIP by utilizing a PIP-Fc fusion for staining of the Fc fragment ${ }^{39}$. Detection of the PIP-Fc revealed that PIP-GalNAc depleted about $60 \%$ of integrins while PIP alone degraded $40 \%$ (Fig. $5 d)$. Nevertheless, PIP-GalNAc had a profound effect on the proliferation of HEPG2 cells compared to the parent binder. PIP-GalNAc was significantly more effective at inhibiting proliferation than PIP at varying concentrations and durations of the treatment (Fig. $5 \mathrm{e}-\mathrm{g}$ ). Moreover, cells treated with PIP-GalNAc displayed aberrant morphology over time. Untreated and PIP treated cells generally displayed epithelial-like clusters, whereas the PIP-GalNAc treated cells formed smaller, circular clusters over the course of 5 days following treatment (Fig. $5 \mathrm{~h})$. Prior work demonstrated that $\alpha_{\mathrm{v}} \beta_{3}$ integrin expression is associated with tumor size, invasion, and metastasis of $\mathrm{HCC}$, and that antisense gene transfections of $\alpha_{v}$ and $\beta_{3}$ integrin reduced proliferation in HEPG2 cells ${ }^{40,41}$. Our results suggest that increased degradation of integrins by LYTACs can result in significantly enhanced functional effects compared to the parent binder alone.

\section{Site-Specific GalNAC-LYTACs improve the pharmacokinetic profile in mice}

Our original LYTACs were constructed by non-specific conjugation of M6Pn polymers to lysine residues on antibodies or Fabs. However, the heterogenous nature of both the polymeric ligands and conjugation chemistry prevented rigorous structure-function relationship studies. Similarly, non-specific functionalization with tri-GalNAc affords heterogeneous LYTACs that are difficult to rigorously analyze for rational improvement. The ability of PIP-GalNAc to promote degradation with a single tri-GalNAc ligand (Fig. 5) suggested that simplified antibody-based LYTACs might be similarly effective and enable the study of architectural features essential for optimal LYTAC activity. Therefore, we generated a panel of GalNAc-LYTACs based on Ctx using site-specific conjugation chemistry via the SMARTag technology, which involves genetic encoding of a reactive aldehyde handle on a specific site of the antibody scaffold ${ }^{42}$. To create a stable linkage between the tri-GalNAc motif and the aldehyde, we utilized a hydrazino iso-Pictet Spangler (HIPS) reaction scheme ${ }^{43,44}$ (Fig. 6a). To determine whether the location of tri-GalNAc ligand on the antibody scaffold would impact the degradation profile, we labeled three different sites of Cetuximab - C-terminus, hinge, and $\mathrm{CH} 1$ heavy chain (Fig. 6b). Conjugation at the hinge resulted in the ligand to antibody ratio of 2, while conjugation in the $\mathrm{C}$-terminus and $\mathrm{CH} 1$ positions resulted in a ligand to antibody ratio of 1 (Extended Data Fig. 11). LYTACs resulting from sitespecific conjugation at the C-terminus and the $\mathrm{CH} 1$ heavy chain of $\mathrm{Ctx}$ demonstrated $>50 \%$ degradation of EGFR, while conjugation at the hinge only showed $40 \%$ degradation despite the increased ligand to antibody ratio (Fig. 6c). Steric hindrance may be an issue in the hinge region for bridging EGFR and ASGPR, resulting in modest differences in degradation efficiency. The degradation efficiency of the site-specific Ctx conjugates was slightly lower than that of the nonspecifically labeled LYTACs. This could imply either that the antibody requires several tri-GalNAc moieties to achieve maximum degradation or that an optimal site for conjugation remains to be identified. We also generated site-specific conjugates based on Pertuzumab (Extended Data Fig.12), and observed that a single tri-GalNAc conjugation at the hinge showed comparable degradation as the non-specific Ptz-GalNAc, while attachment at the C-terminus or the $\mathrm{CH} 1$ domain resulted in less degradation (Fig. 6d). These results indicate that the optimal site of the conjugation may differ between antibodies, potentially due to their different binding sites of the target and the resulting orientation of the LYTAC conjugate between ASGPR and the target.

We asked whether site-specifically labeled conjugates might exhibit altered in vivo clearance profiles. To test this, Balb/c mice were intraperitoneally injected with $5 \mathrm{mg} / \mathrm{kg}$ of Ctx, nonspecifically conjugated Ctx-(GalNAc) ${ }_{10}$, Ctx-C-terminus-(GalNAc) $)_{1}$, or Ctx-CH1-(GalNAc) 1 and plasma was collected at $6,24,48$, and 72 hours to analyze their clearance rate. Ctx- 
(GalNAc) ${ }_{10}$ cleared rapidly before 6 hours (Fig. 6e), implying frequent treatments would be required to maintain reduced EGFR levels given that the degradation was not durable for more than 24 hours in vitro following wash-off after LYTAC treatment (Extended Data Fig. 13). However, site specific conjugates showed an initial clearance followed by sustained presence 72 hours post injection (Fig. 6e,f). In addition, liver and spleen were collected at 72 hours and were probed for the presence of the conjugates. Ctx and Ctx-GalNAc conjugates were present in the liver while only $\mathrm{Ctx}$ was present in the spleen, reaffirming that $\mathrm{Ctx}$-GalNAc conjugates preferentially accumulate in the liver (Fig. 6g). These results demonstrate that site-specific GalNAc-LYTACs may be advantageous in vivo as a result of less frequent dosing than nonspecific conjugates, enhancing the potential for sustained degradation.

\section{Discussion}

An advantage of LYTACs as a protein degradation modality is the ability to tune degradation to a specific cell type expressing a given lysosome targeting receptor. To demonstrate this, we established that LYTACs can be designed to utilize ASGPR for liver cellspecific degradation. GalNAc-LYTACs efficiently ablated EGFR and HER2 in HCC cells. We verified that the mechanism of degradation was through the endo-lysosomal system and dependent on ASGPR internalization. Increased trafficking of proteins to the lysosome did not significantly impact lysosomal health, suggesting that removal of a desired protein does not negatively impact the lysosomal stability or homeostatic capabilities of a given cell and that LYTACs would be applicable to indications where avoiding cell damage is desirable. Co-culture of HCC cells with cells lacking ASGPR demonstrated that GalNAc-LYTACs are indeed capable of cell-specific degradation. GaINAc-LYTACs degraded EGFR and induced more substantial abrogation of downstream kinase signaling than inhibition alone. A synthetic peptide with a single tri-GalNAc moiety was able to degrade integrins and resulted in substantial anti-proliferative effect, which demonstrated that the structural design of LYTACs can be simplified to small conjugates. Broadly, GalNAc-LYTACs represent a strategy for receptor-mediated and cell-specific degradation that can be applied to membrane proteins relevant in liver diseases, such as HCC, that does not depend on cell penetrance or carrier-degradation.

Additionally, we showed that GaINAc-LYTACs are far better at internalizing extracellular cargoes than M6Pn-LYTACs in HEPG2 cells, likely resulting from the higher surface expression of ASGPR relative to Cl-M6PR in hepatocytes. Despite the difference in surface levels of these receptors, GalNAc- and M6Pn-LYTACs performed comparably in membrane protein degradation assays. This observation suggests factors other than the expression levels of the recycling receptors modulate the degree of degradation. These factors might include the distinct sorting of these receptors, the rate of target release from the receptor to the lysosome, the rate of target turnover, or the rate of the receptor trafficking. Further studies that probe the mechanistic features influencing degradation mediated by endocytic receptors are needed, and may provide insight into rational strategies to enhance degradation efficiency.

GalNAc-LYTACs serve as an example for applications to other recycling receptors that may be exploited for cell-specific degradation, such as mannose receptors for macrophage specific targeting ${ }^{45}$ and CD22 for B-cell selective degradation ${ }^{46}$. Additional discovery of recycling receptors with distinct and exclusive localization would expand the range of tissues or cells that LYTACs can target with selectivity. Recently, antibody-PROTAC conjugates demonstrated HER2-dependent degradation via a mechanism of delivery similar to antibody-drug conjugates ${ }^{47}$. However, a general approach for tissue-specific degradation utilizing the UPS or intracellular autophagy machinery would require ligand development campaigns for tissue-restricted E3 ligases or autophagy regulators. ${ }^{48,49}$ We envision that further structure-function studies in combination with mechanistic elucidation will determine the optimal architecture of LYTACs and provide structural understanding of degradation driven by lysosome targeting receptors. 


\section{Materials and Methods}

\section{General Chemical Synthesis Procedures}

Reagent-grade chemical reagents were purchased from Carbosynth, Sigma Aldrich, TCl, Click Chemistry Tools, and TCl. All chemical reactions were performed in standard, flame-dried glassware capped with rubber septa under an inert atmosphere of nitrogen unless stated otherwise. Stainless steel syringes or cannulae were used to transfer moisture-sensitive liquids. Anhydrous solvents (dichloromethane and $\mathrm{N}, \mathrm{N}$-dimethylformamide) were prepared by passage through an activated alumina column. Thin layer chromatography (TLC) was conducted on precoated glass plates covered with $0.2 \mathrm{~mm}$ silica gel for monitoring reactions. TLC was visualized with UV light, $5 \% \mathrm{H}_{2} \mathrm{SO}_{4}$ in $\mathrm{MeOH}$, and ninhydrin stain. Reaction mixtures were purified via column chromatography using Biotage SNAP KP-Sil or Ultra C18 cartridges (10-100g) with a Biotage Isolera Prime $\mathrm{ACl}$ automated fraction collector.

\section{Cell Lines}

Adherent cells were cultured in T75 flasks or $15 \mathrm{~cm}$ plates at $37{ }^{\circ} \mathrm{C}$ in a $5 \% \mathrm{CO}_{2}$ atmosphere. HEP3B (ATCC), HUH7 (JCRB), and HeLa-GFP (MyBioSource) were cultured in DMEM supplemented with $10 \%$ fetal bovine serum (FBS) and $1 \%$ penicillin/streptomycin. HEPG2 (ATCC) were cultured in DMEM with low glucose supplemented with $10 \%$ fetal bovine serum (FBS) and $1 \%$ penicillin/streptomycin. Expi293 cells expressing formylglycine-generating enzyme from $M$. tuberculosis (tbFGE) were a generous gift from Melissa Gray, and were cultured with Expi293 Expression Medium (Thermo Fischer) supplemented with $2 \mu \mathrm{g} / \mathrm{ml}$ puromycin in $250 \mathrm{ml}$ polycarbonate shaker flasks (Corning), rotating $120 \mathrm{rpm}$ at $37{ }^{\circ} \mathrm{C}$ and $8 \% \mathrm{CO}_{2}$.

\section{HEPG2 Internalization Assay}

HEPG2 cells were plated $(100,000$ cells/well in a 24 -well plate) 2 days before the experiment. Cells were incubated with $200 \mu$ of complete growth media with 50 nM Rabbit IgG-647 and 25 nM goat anti-rabbit, goat anti-rabbit-M6Pn, or goat-anti-rabbit-GalNAc for 1 hour. Following incubation, cells were washed with PBS three times, trypsinized, then transferred to a 96 well Vbottom plate. The cells were washed 3 times with PBS $+0.5 \%$ BSA $+5 \mathrm{mM}$ EDTA, then incubated with Sytox Green for 15 minutes on ice prior to flow cytometry analysis.

\section{HEPG2 Co-localization Live-Cell Imaging}

HEPG2 cells were plated (30,000 cells/well in an 8-well Labtek) 2 days before the experiment. Cells were incubated with $200 \mu$ of complete growth media with 50 nM Rabbit IgG-647 and 25 nM goat anti-rabbit, goat anti-rabbit-M6Pn, or goat-anti-rabbit-GalNAc for 1 hour. Following incubation, cells were washed with HBSS then incubated with $50 \mathrm{nM}$ Lysotracker in HBSS for 30 minutes at $37{ }^{\circ} \mathrm{C}$. Cells were then washed with HBSS 3 times, incubated with Hoescht for 5 minutes, and imaged by confocal microscopy.

\section{Protein Degradation Analysis by Western Blot}

Adherent cells were plated $(100,000$ cells/well in a 24 -well plate) one day before the experiment. Cells were incubated with $250 \mu \mathrm{l}$ of complete growth media with $10 \mathrm{nM}$ LYTAC or controls for indicated time. Cells were then washed with DPBS 3 times and lysed with RIPA buffer supplemented with protease inhibitor cocktail (Roche), $0.1 \%$ Benzonase (Millipore-Sigma), and phosphatase inhibitor cocktail (Cell Signaling Technologies) on ice for 30 minutes. The cells were scraped, transferred to Eppendorf tubes, and spun down at $21,000 \mathrm{~g}$ for 15 minutes at $4{ }^{\circ} \mathrm{C}$. The supernatant was collected and the protein concentration was determined by BCA assay (Pierce). Equal amounts of lysates were loaded onto 4-12\% Bis-Tris gel and separated by sodium dodecyl sulfate-polacrylamide gel electrophoresis (SDS-PAGE). Then, the gel was transferred onto a 
nitrocellulose membrane and stained with REVERT Total Protein Stain (LI-COR), then blocked with Odyssey Blocking Buffer (TBS) (LI-COR) for 1 hour at rt. The membrane was incubated with primary antibody overnight at $4{ }^{\circ} \mathrm{C}$, washed 3 times with TBS-T. Subsequently, the membrane was incubated with secondary antibody for 1 hour at $\mathrm{rt}$, and washed 3 times with TBS-T for visualization with an Odyssey CLx Imager (LI-COR). Image Studio (LI-COR) was used to quantify band intensities.

\section{Cell-surface Degradation Analysis by Flow Cytometry}

Adherent cells were plated $(100,000$ cells/well in a 24 -well plate) one day before the experiment. Cells were incubated with $250 \mu \mathrm{l}$ of complete growth media with $10 \mathrm{nM}$ LYTAC or controls for indicated time. Cells were then washed with PBS 3 times, trypsinized for $<5$ minutes, and transferred to a 96-well V-bottom plate. The cells were washed 3 times with PBS $+0.5 \%$ BSA + $5 \mathrm{mM}$ EDTA (FACS buffer) and incubated with primary antibody for 30 minutes on ice. The cells were washed 3 times with PBS $+0.5 \%$ BSA +5 mM EDTA (FACS buffer) and incubated with secondary antibody for 30 minutes on ice. After washing 3 times with FACS buffer, cells were incubated with either Sytox Green or Sytox Blue for 15 minutes on ice. Flow cytometry was performed on either a BD LSR II or BD Accuri C6 Plus, and FlowJo software was used to gate on single cells and live cells for analysis.

\section{Cell-surface Integrin Degradation Analysis by Flow Cytometry}

HEPG2 cells were plated (100,000 cells/well in a 24-well plate) one day before the experiment. Cells were incubated with $250 \mu \mathrm{l}$ of complete growth media with $100 \mathrm{nM}$ PIP or PIP-GalNAc for 48 hours. Cells were washed with integrin binding buffer $(20 \mathrm{mM}$ Tris, $\mathrm{pH} 7.4,0.1 \% \mathrm{BSA}, 150 \mathrm{mM}$ $\mathrm{NaCl}, 2 \mathrm{mM} \mathrm{CaCl}_{2}, 1 \mathrm{mM} \mathrm{MgCl}, 1 \mathrm{mM} \mathrm{MnCl}_{2}$ ) and stained with primary antibodies on ice. For PIP-Fc staining, cells were washed with $5 \mathrm{mM}$ EDTA in PBS to remove bound PIP following treatments, then stained with PIP-Fc (mouse IgG2a). After primary incubation, cells were processed and prepared for flow cytometry analysis as shown above.

\section{Confocal Microscopy for Membrane Protein Degradation}

Adherent cells were plated (30,000 cells/well in an 8-well Labtek) one day before the experiment. Cells were incubated with $200 \mu \mathrm{l}$ of complete growth media with $10 \mathrm{nM}$ LYTAC or controls for indicated time. Cells were then washed with DPBS and cells were stained with Membrite using the manufacturer's protocol. Cells were fixed with 4\% paraformaldehyde in PBS for 20 minutes at $\mathrm{rt}$, washed 3 times, and permeabilized with $0.1 \%$ Triton for 5 minutes at $4{ }^{\circ} \mathrm{C}$. Cells were washed 3 times with DPBS and blocked in $10 \%$ goat serum in PBS for 1 hour at rt, and incubated with primary antibody overnight at $4{ }^{\circ} \mathrm{C}$. Cells were washed with DPBS, then incubated with secondary antibody and DAPI for 1 hour at rt. Cells were washed with DPBS and imaged with Nikon A1R confocal microscope using Plan Fluor 60x oil immersion 1.30-numerical aperture objective. 405$\mathrm{nm}$ violet laser, 488-nm blue laser, 561-nm green laser, and 639-nm red laser were used.

\section{SiRNA knockdown}

HEP3B (75,000 cells/well in 24 well plate) were transfected with 20 pmoles of siRNA (Dharmacon) and jetPRIME reagent using manufacturer's specifications.

\section{EGF Stimulated Phosphorylation}

HEP3B cells were plated $(100,000$ cells/well in a 24 -well plate) one day before the experiment. Cells were incubated with $250 \mu \mathrm{l}$ of complete growth media with $10 \mathrm{nM}$ LYTAC or controls for 48 hours. Following incubation, cells were washed 3 times with PBS, and 50 or $100 \mathrm{ng} / \mathrm{ml}$ of EGF was added and cells were incubated for $1 \mathrm{hr}$ at $37^{\circ} \mathrm{C}$. Cells were washed and lysed for western blot analysis. 


\section{Co-Culture Assay}

HEP3B (100,000 cells/well) and GFP-HeLa (20,000 cells/well) cells were co-cultured in 24-well plate. Cells were then treated with $50 \mathrm{nM}$ of Ctx conjugates for 48 hours and surface-level EGFR was assessed by flow cytometry.

\section{Anti-proliferation Assay}

HEPG2 cells $(100,000$ cells/well in a 24 -well plate) were treated with $100 \mathrm{nM}$ of PIP or PIPGalNAc. After treatments were added, cells were imaged every 4 hours for 44 hours (for concentration studies) or for 5 days in the IncuCyte S3 Live-Cell Analysis system using the Phase imaging channel and 10X objective setting.

The following analysis was used to quantify Phase Confluence (\%) in the Incucyte software: Segmentation Adjustment $=1$, Cleanup- Hole Fill $\left(\mu m^{2}\right)=300$, Filters- Area Minimum $\left(\mu \mathrm{m}^{2}\right)=150$. No other constraints were selected.

Percent proliferation was then calculated by normalizing Phase Confluence (\%) values. Specifically, at any given timepoint $n$ in the treatment time course $(\mathrm{t}=0 \rightarrow \mathrm{t}=n)$, the change in Confluence from $\mathrm{t}=0$ to $\mathrm{t}=n\left(\Delta\right.$ Confluence $\left._{\mathrm{t}=n}\right)$ was calculated for each well as follows:

$\Delta$ Confluence $_{\mathrm{t}=n}$ of well $x=\left(\right.$ Confluence $_{\mathrm{t}=n}$ of well $\left.x\right)$ - (Confluence $\mathrm{t}=0$ of well $\left.x\right)$, where $x$ represents any given well in the experiment. This ensures the value of each well is set to 0 at $t=$ 0 . The average $\Delta$ Confluence at the final time point of the untreated wells was set as the "Max Value" (equivalent to $100 \%$ Proliferation). Finally, data were normalized as follows:

$\%$ Proliferation $_{\mathrm{t}=n}$ of well $\mathrm{x}=\left(\Delta\right.$ Confluence $_{\mathrm{t}=n}$ of well $\left.\mathrm{x}\right) /($ Max Value $)$.

\section{Site-Specific Antibody conjugation}

HIPS-azide ${ }^{43,44}$ was resuspended in DMSO to $5 \mathrm{mg} / \mathrm{ml}$ and was added to aldehyde-tagged antibody in citrate buffer. The reaction was agitated overnight at $37^{\circ} \mathrm{C}$ protected from light. Upon reaction completion, the reaction mixture was filtered using a $40 \mathrm{kDa}$ Zeba size exclusion column. Tri-GalNAc DBCO (50 equiv.) was then added to antibody labeled with HIPS-azide (>1 mg/ml) and the reaction mixture was incubated at $r$ for 3 days in dark. The reaction mixture was filtered using a $40 \mathrm{kDa}$ Zeba size exclusion column and the protein concentration was determined from $\mathrm{A}_{280}$ using Nanodrop 200 Spectrophotometer.

\section{In vivo Pharmacokinetic Study}

Female BALB/c (6-8 weeks old, Jackson Laboratory) were injected intraperitoneally with $5 \mathrm{mg} / \mathrm{kg}$ Ctx or Ctx conjugates. Blood was collected at $6,24,48,72 \mathrm{~h}$ via tail-bleed and plasma was separated. $2 \mu \mathrm{l}$ of plasma was loaded onto SDS-PAGE (4-12\% Bis-Tris gel) and transferred onto a nitrocellulose membrane for detecting human antibody presence (800CW goat anti-human, LICOR). Organs were harvested at 72 hours, lysed with RIPA buffer supplemented with protease inhibitor and $0.1 \%$ Benzonase. Protein concentration was determined using BCA and $50 \mu \mathrm{g}$ of total protein were loaded onto SDS-PAGE (4-12\% Bis-Tris gel) and transferred onto a nitrocellulose membrane for detecting human antibody presence (800CW goat anti-human, LICOR).

Antibodies
\begin{tabular}{|l|l|l|}
\hline Antibody & Source (\#) & Usage, Dilution \\
\hline Anti-Rabbit IgG & Bio X Cell (BE0095) & Functional \\
\hline Goat Anti-Rabbit IgG & $\begin{array}{l}\text { Jackson ImmunoResearch } \\
(111-005-144)\end{array}$ & Functional \\
\hline Rabbit-anti-EGFR & CST (D38B1) & WB, 1:1000 \\
\hline Mouse anti-Vinculin & Bio-Rad (V284) & WB, 1:1000 \\
\hline Mouse-anti-EGFR & Invitrogen (MA513319) & Flow Cytometry, $10 \mu \mathrm{g} / \mathrm{ml}$ \\
\hline
\end{tabular}




\begin{tabular}{|l|l|l|}
\hline $\begin{array}{l}\text { Goat anti-mouse IgG-Alexa } \\
\text { Fluor } 647\end{array}$ & $\begin{array}{l}\text { Jackson ImmunoResearch } \\
(115-605-071)\end{array}$ & Flow cytometry, IF, 1:375 \\
\hline Cetuximab & Eli Lilly & Functional \\
\hline $\begin{array}{l}\text { Phospho-EGF Receptor } \\
\text { (Tyr1068) }\end{array}$ & CST (2234S) & $1: 1000$ \\
\hline Phospho-Akt (Ser473) & CST (9271S) & $1: 1000$ \\
\hline $\begin{array}{l}\text { Phospho-p44/42 MAPK } \\
\text { (Erk1/2) (Thr202/Tyr204) }\end{array}$ & CST (4376S) & $1: 1000$ \\
\hline ALIX & BioLegend (634502) & IF, 1:500 \\
\hline Pertuzumab & Selleck Chemicals (A2008) & Functional \\
\hline HER2/ErbB2 & CST (2242S) & WB, $1: 1000$ \\
\hline HER2 & CST (2165S) & IF $1: 100$ \\
\hline Alpha V Beta 3 integrin & R\&D (MAB3050) & $1 \mu g / 100 \mu l$ \\
\hline Alpha V Beta 5 integrin & R\&D (MAB2528) & $1 \mu g / 100 \mu l$ \\
\hline $\begin{array}{l}\text { IRDye 800CW Goat-anti- } \\
\text { rabbit IgG }(H+L)\end{array}$ & LI-COR (926-32211) & WB, 1:10000 \\
\hline $\begin{array}{l}\text { IRDye 800CW Goat-anti- } \\
\text { mouse IgG }(H+L)\end{array}$ & LI-COR & WB, 1:10000 \\
\hline $\begin{array}{l}\text { IRDye 800CW Goat-anti- } \\
\text { human IgG (H+L) }\end{array}$ & LI-COR & WB, 1:1000 \\
\hline
\end{tabular}




\section{References}

1. Krönke, J., Udeshi, N. D., Narla, A., Grauman, P., Hurst, S. N., McConkey, M., Svinkina, T., Heckl, D., Comer, E., Li, X., Ciarlo, C., Hartman, E., Munshi, N., Schenone, M., Schreiber, S. L., Carr, S. A. \& Ebert, B. L. Lenalidomide Causes Selective Degradation of IKZF1 and IKZF3 in Multiple Myeloma Cells. Science 343, 301-305 (2014).

2. Lu, G., Middleton, R. E., Sun, H., Naniong, M., Ott, C. J., Mitsiades, C. S., Wong, K.-K., Bradner, J. E. \& Kaelin, W. G. The Myeloma Drug Lenalidomide Promotes the CereblonDependent Destruction of Ikaros Proteins. Science 343, 305-309 (2014).

3. Sakamoto, K. M., Kim, K. B., Kumagai, A., Mercurio, F., Crews, C. M. \& Deshaies, R. J. Protacs: Chimeric molecules that target proteins to the Skp1-Cullin-F box complex for ubiquitination and degradation. Proc. Natl. Acad. Sci. 98, 8554-8559 (2001).

4. Winter, G. E., Buckley, D. L., Paulk, J., Roberts, J. M., Souza, A., Dhe-Paganon, S. \& Bradner, J. E. Phthalimide conjugation as a strategy for in vivo target protein degradation. Science 348, 1376-1381 (2015).

5. Nabet, B., Roberts, J. M., Buckley, D. L., Paulk, J., Dastjerdi, S., Yang, A., Leggett, A. L., Erb, M. A., Lawlor, M. A., Souza, A., Scott, T. G., Vittori, S., Perry, J. A., Qi, J., Winter, G. E., Wong, K.-K., Gray, N. S. \& Bradner, J. E. The dTAG system for immediate and targetspecific protein degradation. Nat. Chem. Biol. 14, 431-441 (2018).

6. Nabet, B., Ferguson, F. M., Seong, B. K. A., Kuljanin, M., Leggett, A. L., Mohardt, M. L., Robichaud, A., Conway, A. S., Buckley, D. L., Mancias, J. D., Bradner, J. E., Stegmaier, K. \& Gray, N. S. Rapid and direct control of target protein levels with VHL-recruiting dTAG molecules. bioRxiv 2020.03.13.980946 (2020). doi:10.1101/2020.03.13.980946

7. Clift, D., McEwan, W. A., Labzin, L. I., Konieczny, V., Mogessie, B., James, L. C. \& Schuh, M. A Method for the Acute and Rapid Degradation of Endogenous Proteins. Cell 171, 16921706.e18 (2017).

8. Naito, M., Ohoka, N. \& Shibata, N. SNIPERs-Hijacking IAP activity to induce protein degradation. Drug Discov. Today Technol. 31, 35-42 (2019).

9. Takahashi, D., Moriyama, J., Nakamura, T., Miki, E., Takahashi, E., Sato, A., Akaike, T., Itto-Nakama, K. \& Arimoto, H. AUTACs: Cargo-Specific Degraders Using Selective Autophagy. Mol. Cell S109727651930694X (2019). doi:10.1016/j.molcel.2019.09.009

10. Li, Z., Wang, C., Wang, Z., Zhu, C., Li, J., Sha, T., Ma, L., Gao, C., Yang, Y., Sun, Y., Wang, J., Sun, X., Lu, C., Difiglia, M., Mei, Y., Ding, C., Luo, S., Dang, Y., Ding, Y., Fei, Y. \& Lu, B. Allele-selective lowering of mutant HTT protein by HTT-LC3 linker compounds. Nature 575, 203-209 (2019).

11. Li, Z., Zhu, C., Ding, Y., Fei, Y. \& Lu, B. ATTEC: a potential new approach to target proteinopathies. Autophagy 16, 185-187 (2020).

12. Mullard, A. First targeted protein degrader hits the clinic. Nat. Rev. Drug Discov. 18, 237 (2019).

13. Banik, S. M., Pedram, K., Wisnovsky, S., Ahn, G., Riley, N. M. \& Bertozzi, C. R. Lysosometargeting chimaeras for degradation of extracellular proteins. Nature 1-7 (2020). doi:10.1038/s41586-020-2545-9

14. Ghosh, P., Dahms, N. M. \& Kornfeld, S. Mannose 6-phosphate receptors: new twists in the tale. Nat. Rev. Mol. Cell Biol. 4, 202 (2003).

15. Spiess, M. The asialoglycoprotein receptor: a model for endocytic transport receptors. Biochemistry 29, 10009-10018 (1990).

16. Park, E. I., Mi, Y., Unverzagt, C., Gabius, H.-J. \& Baenziger, J. U. The asialoglycoprotein receptor clears glycoconjugates terminating with sialic acida2,6GalNAc. Proc. Natl. Acad. Sci. 102, 17125-17129 (2005).

17. Stockert, R. J. The asialoglycoprotein receptor: relationships between structure, function, and expression. Physiol. Rev. 75, 591-609 (1995). 
18. Matsuda, S., Keiser, K., Nair, J. K., Charisse, K., Manoharan, R. M., Kretschmer, P., Peng, C. G., V. Kel'in, A., Kandasamy, P., Willoughby, J. L. S., Liebow, A., Querbes, W., Yucius, K., Nguyen, T., Milstein, S., Maier, M. A., Rajeev, K. G. \& Manoharan, M. siRNA Conjugates Carrying Sequentially Assembled Trivalent N-Acetylgalactosamine Linked Through Nucleosides Elicit Robust Gene Silencing In Vivo in Hepatocytes. ACS Chem. Biol. 10, 1181-1187 (2015).

19. Springer, A. D. \& Dowdy, S. F. GalNAc-siRNA Conjugates: Leading the Way for Delivery of RNAi Therapeutics. Nucleic Acid Ther. 28, 109-118 (2018).

20. Zimmermann, T. S., Karsten, V., Chan, A., Chiesa, J., Boyce, M., Bettencourt, B. R., Hutabarat, R., Nochur, S., Vaishnaw, A. \& Gollob, J. Clinical Proof of Concept for a Novel Hepatocyte-Targeting GalNAc-siRNA Conjugate. Mol. Ther. 25, 71-78 (2017).

21. Prakash, T. P., Graham, M. J., Yu, J., Carty, R., Low, A., Chappell, A., Schmidt, K., Zhao, C., Aghajan, M., Murray, H. F., Riney, S., Booten, S. L., Murray, S. F., Gaus, H., Crosby, J., Lima, W. F., Guo, S., Monia, B. P., Swayze, E. E. \& Seth, P. P. Targeted delivery of antisense oligonucleotides to hepatocytes using triantennary $\mathrm{N}$-acetyl galactosamine improves potency 10-fold in mice. Nucleic Acids Res. 42, 8796-8807 (2014).

22. Kanasty, R., Dorkin, J. R., Vegas, A. \& Anderson, D. Delivery materials for siRNA therapeutics. Nat. Mater. 12, 967-977 (2013).

23. Lee, Y. C., Townsend, R. R., Hardy, M. R., Lönngren, J., Arnarp, J., Haraldsson, M. \& Lönn, $\mathrm{H}$. Binding of synthetic oligosaccharides to the hepatic Gal/GalNAc lectin. Dependence on fine structural features. J. Biol. Chem. 258, 199-202 (1983).

24. Nair, J. K., Willoughby, J. L. S., Chan, A., Charisse, K., Alam, Md. R., Wang, Q., Hoekstra, M., Kandasamy, P., Kel'in, A. V., Milstein, S., Taneja, N., O'Shea, J., Shaikh, S., Zhang, L., van der Sluis, R. J., Jung, M. E., Akinc, A., Hutabarat, R., Kuchimanchi, S., Fitzgerald, K., Zimmermann, T., van Berkel, T. J. C., Maier, M. A., Rajeev, K. G. \& Manoharan, M. Multivalent N-Acetylgalactosamine-Conjugated siRNA Localizes in Hepatocytes and Elicits Robust RNAi-Mediated Gene Silencing. J. Am. Chem. Soc. 136, 16958-16961 (2014).

25. Huang, X., Leroux, J.-C. \& Castagner, B. Well-Defined Multivalent Ligands for Hepatocytes Targeting via Asialoglycoprotein Receptor. Bioconjug. Chem. 28, 283-295 (2017).

26. Huang, Y. Preclinical and Clinical Advances of GalNAc-Decorated Nucleic Acid Therapeutics. Mol. Ther. Nucleic Acids 6, 116-132 (2017).

27. Fitzgerald, K., White, S., Borodovsky, A., Bettencourt, B. R., Strahs, A., Clausen, V., Wijngaard, P., Horton, J. D., Taubel, J., Brooks, A., Fernando, C., Kauffman, R. S., Kallend, D., Vaishnaw, A. \& Simon, A. A Highly Durable RNAi Therapeutic Inhibitor of PCSK9. http://dx.doi.org.stanford.idm.oclc.org/10.1056/NEJMoa1609243 (2016). doi:10.1056/NEJMoa1609243

28. Probert, M. A., Zhang, J. \& Bundle, D. R. Synthesis of $\alpha$ - and $\beta$-linked tyvelose epitopes of the Trichinella spiralis glycan: 2-acetamido-2-deoxy-3-O-(3,6-dideoxy-d-arabinohexopyranosyl)- $\beta$-d-galactopyranosides. Carbohydr. Res. 296, 149-170 (1996).

29. Banik, S., Pedram, K., Wisnovsky, S., Riley, N. \& Bertozzi, C. Lysosome Targeting Chimeras (LYTACs) for the Degradation of Secreted and Membrane Proteins. (2019). doi:10.26434/chemrxiv.7927061.v1

30. Ezzoukhry, Z., Louandre, C., Trécherel, E., Godin, C., Chauffert, B., Dupont, S., Diouf, M., Barbare, J.-C., Mazière, J.-C. \& Galmiche, A. EGFR activation is a potential determinant of primary resistance of hepatocellular carcinoma cells to sorafenib. Int. J. Cancer 131, 29612969 (2012).

31. Blivet-Van Eggelpoël, M.-J., Chettouh, H., Fartoux, L., Aoudjehane, L., Barbu, V., Rey, C., Priam, S., Housset, C., Rosmorduc, O. \& Desbois-Mouthon, C. Epidermal growth factor receptor and HER-3 restrict cell response to sorafenib in hepatocellular carcinoma cells. $J$. Hepatol. 57, 108-115 (2012). 
32. Baselga, J., Trigo, J. M., Bourhis, J., Tortochaux, J., Cortés-Funes, H., Hitt, R., Gascón, P., Amellal, N., Harstrick, A. \& Eckardt, A. Phase II Multicenter Study of the Antiepidermal Growth Factor Receptor Monoclonal Antibody Cetuximab in Combination With PlatinumBased Chemotherapy in Patients With Platinum-Refractory Metastatic and/or Recurrent Squamous Cell Carcinoma of the Head and Neck. J. Clin. Oncol. 23, 5568-5577 (2005).

33. Vermorken, J. B., Trigo, J., Hitt, R., Koralewski, P., Diaz-Rubio, E., Rolland, F., Knecht, R., Amellal, N., Schueler, A. \& Baselga, J. Open-Label, Uncontrolled, Multicenter Phase II Study to Evaluate the Efficacy and Toxicity of Cetuximab As a Single Agent in Patients With Recurrent and/or Metastatic Squamous Cell Carcinoma of the Head and Neck Who Failed to Respond to Platinum-Based Therapy. J. Clin. Oncol. 25, 2171-2177 (2007).

34. Bondeson, D. P., Smith, B. E., Burslem, G. M., Buhimschi, A. D., Hines, J., Jaime-Figueroa, S., Wang, J., Hamman, B. D., Ishchenko, A. \& Crews, C. M. Lessons in PROTAC Design from Selective Degradation with a Promiscuous Warhead. Cell Chem. Biol. 25, 78-87.e5 (2018).

35. Shi, J.-H., Guo, W.-Z., Jin, Y., Zhang, H.-P., Pang, C., Li, J., Line, P.-D. \& Zhang, S.-J. Recognition of HER2 expression in hepatocellular carcinoma and its significance in postoperative tumor recurrence. Cancer Med. 8, 1269-1278 (2019).

36. Kimura, R. H., Levin, A. M., Cochran, F. V. \& Cochran, J. R. Engineered cystine knot peptides that bind $\alpha \vee \beta 3$, $\alpha \vee \beta 5$, and $\alpha 5 \beta 1$ integrins with low-nanomolar affinity. Proteins Struct. Funct. Bioinforma. 77, 359-369 (2009).

37. Desgrosellier, J. S. \& Cheresh, D. A. Integrins in cancer: biological implications and therapeutic opportunities. Nat. Rev. Cancer 10, 9-22 (2010).

38. Cox, N., Kintzing, J. R., Smith, M., Grant, G. A. \& Cochran, J. R. Integrin-Targeting Knottin Peptide-Drug Conjugates Are Potent Inhibitors of Tumor Cell Proliferation. Angew. Chem. Int. Ed. 55, 9894-9897 (2016).

39. Kwan, B. H., Zhu, E. F., Tzeng, A., Sugito, H. R., Eltahir, A. A., Ma, B., Delaney, M. K., Murphy, P. A., Kauke, M. J., Angelini, A., Momin, N., Mehta, N. K., Maragh, A. M., Hynes, R. O., Dranoff, G., Cochran, J. R. \& Wittrup, K. D. Integrin-targeted cancer immunotherapy elicits protective adaptive immune responses. J. Exp. Med. 214, 1679-1690 (2017).

40. Jin, Y., Chen, J., Feng, Z., Zhang, Z., Fan, W., Wang, Y. \& Li, J. OPN and avß3 expression are predictors of disease severity and worse prognosis in hepatocellular carcinoma. PloS One 9, e87930 (2014).

41. Li, J., Tan, H., Dong, X., Xu, Z., Shi, C., Han, X., Jiang, H., Krissansen, G. W. \& Sun, X. Antisense integrin $\alpha V$ and $\beta 3$ gene therapy suppresses subcutaneously implanted hepatocellular carcinomas. Dig. Liver Dis. 39, 557-565 (2007).

42. Rabuka, D., Rush, J. S., deHart, G. W., Wu, P. \& Bertozzi, C. R. Site-specific chemical protein conjugation using genetically encoded aldehyde tags. Nat. Protoc. 7, 1052-1067 (2012).

43. Agarwal, P., Kudirka, R., Albers, A. E., Barfield, R. M., de Hart, G. W., Drake, P. M., Jones, L. C. \& Rabuka, D. Hydrazino-Pictet-Spengler Ligation as a Biocompatible Method for the Generation of Stable Protein Conjugates. Bioconjug. Chem. 24, 846-851 (2013).

44. Gray, M., Stanczak, M. A., Xiao, H., Pijnenborg, J. F. A., Mantuano, N. R., Malaker, S. A., Weidenbacher, P. A., Miller, C. L., Tanzo, J. T., Ahn, G., Woods, E. C., Läubli, H. \& Bertozzi, C. Targeted Desialylation Overcomes Glyco-Immune Checkpoints and Potentiates the Anticancer Immune Response in Vivo. Nature Chem Bio. In press (2020). doi:10.26434/chemrxiv.8187146.v2

45. Stahl, P. D. The Macrophage Mannose Receptor: Current Status. Am. J. Respir. Cell Mol. Biol. 2, 317-318 (1990).

46. O'Reilly, M. K., Tian, H. \& Paulson, J. C. CD22 Is a Recycling Receptor That Can Shuttle Cargo between the Cell Surface and Endosomal Compartments of B Cells. J. Immunol. 186, 1554-1563 (2011). 
47. Maneiro, M., Forte, N., Shchepinova, M. M., Kounde, C. S., Chudasama, V., Baker, J. R. \& Tate, E. W. Antibody-PROTAC conjugates enable HER2-dependent targeted protein degradation of BRD4. ACS Chem. Biol. (2020). doi:10.1021/acschembio.0c00285

48. Lai, A. C. \& Crews, C. M. Induced protein degradation: an emerging drug discovery paradigm. Nat. Rev. Drug Discov. 16, 101-114 (2017).

49. Schapira, M., Calabrese, M. F., Bullock, A. N. \& Crews, C. M. Targeted protein degradation: expanding the toolbox. Nat. Rev. Drug Discov. 1-15 (2019). doi:10.1038/s41573-019-0047-y 


\section{Acknowledgements}

We thank Melissa A. Gray for providing FGE-expressing Expi293 cells and her expertise in sitespecific antibody conjugations. We thank Melissa A. Gray and Julia T. Tanzo for providing HIPS-azide and the Cochran laboratory for providing PIP-Fc (mlgG2a). We thank Sharon Pitteri and Ken Lau (Stanford Canary Center) for performing MALDI-TOF-MS characterization and analysis. We thank Kayvon Pedram for helpful discussions. We thank Theresa McLaughlin and Stanford University Mass Spectrometry for HRMS characterization.

\section{Funding}

This work was supported in part by National Institutes of Health grant R01GM058867 to C.R.B and a St. Baldrick's / Stand Up 2 Cancer Pediatric Dream Team Translational Cancer Research Grant to J.R.C. G.A. was supported by a National Science Foundation Graduate Research Fellowship. S.M.B was supported by a National Institute of General Medical Sciences F32 Postdoctoral Fellowship. C.L.M. was supported by a National Science Foundation Graduate Research Fellowship. N.M.R. was supported by National Institutes of Health grant K00CA21245403. Stand Up 2 Cancer is a program of the Entertainment Industry Foundation administered by the American Association for Cancer Research.

\section{Author contributions}

G.A., S.M.B., and C.R.B. conceived the project. G.A., S.M.B., C.L.M., and N.M.R. carried out experiments and interpreted data. J.R.C. oversaw and provided insights and materials. G.A. and C.R.B. wrote the manuscript with input from all authors. C.R.B. provided supervision.

\section{Data Availability}

All data that supported the findings of this study are available from the corresponding author upon request.

\section{Competing interests}

G.A., S.M.B., and C.R.B. are included as co-inventors on a patent application relating to lysosome targeting chimeras owned by Stanford University. C.R.B. is a co-founder and Scientific Advisory Board member of Palleon Pharmaceuticals, Enable Bioscience, Redwood Biosciences (a subsidiary of Catalent), InterVenn Biosciences, and Lycia Therapeutics, and a member of the Board of Directors of Eli Lilly \& Company. J.R.C. is a founder of xCella Biosciences and Combangio Inc. and co-founder and director of Trapeze Therapeutics. 
a

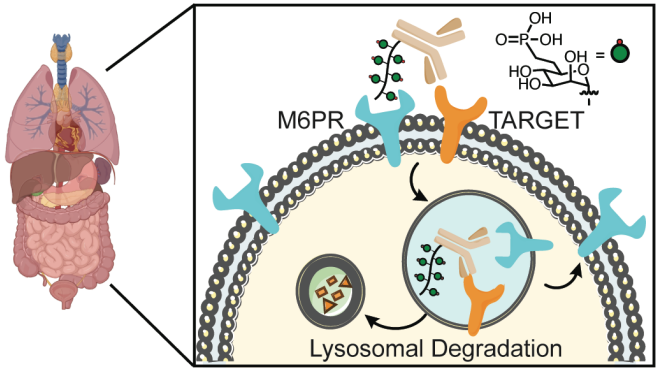

1st Generation Lysosomal Targeting Chimeras (LYTACs): M6PR has broad tissue distribution

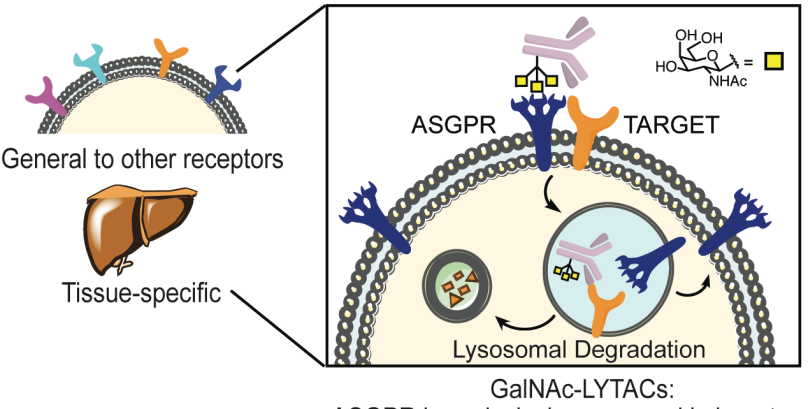

ASGPR is exclusively expressed in hepatocytes b

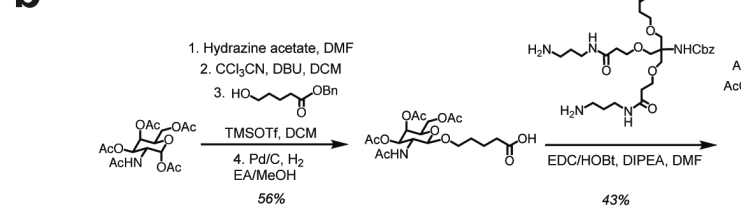

$43 \%$
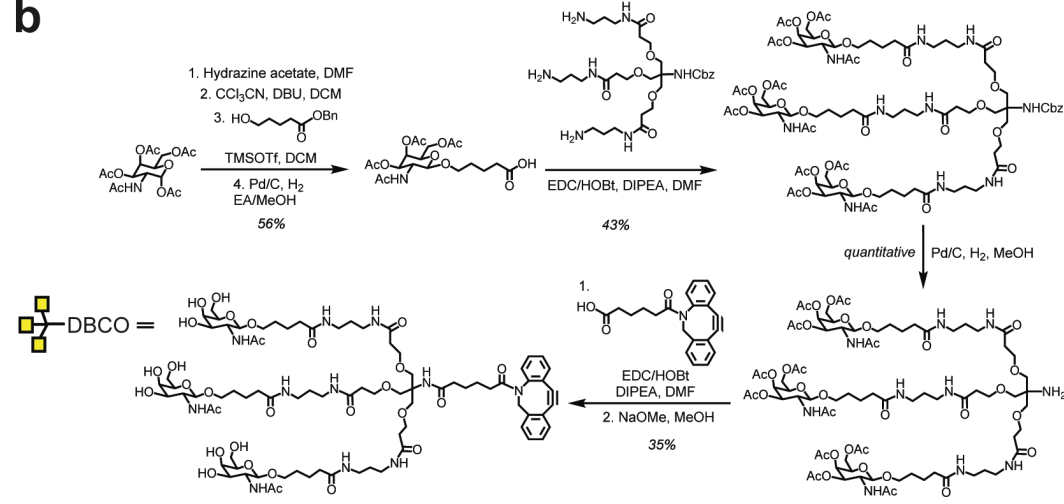

C

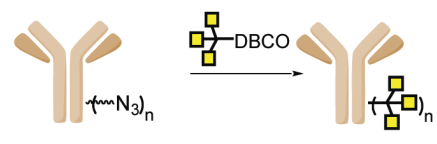

d

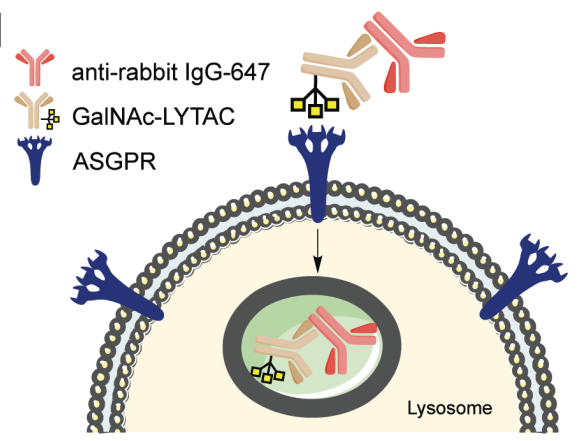

f e

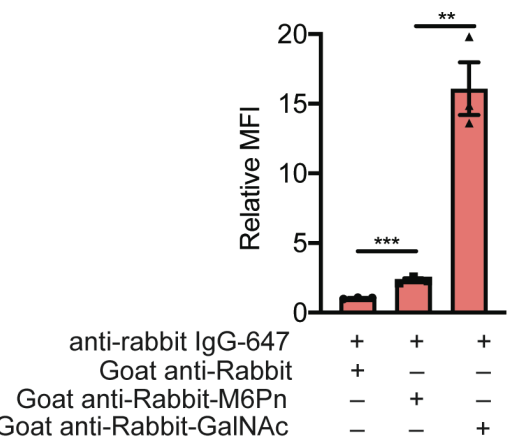

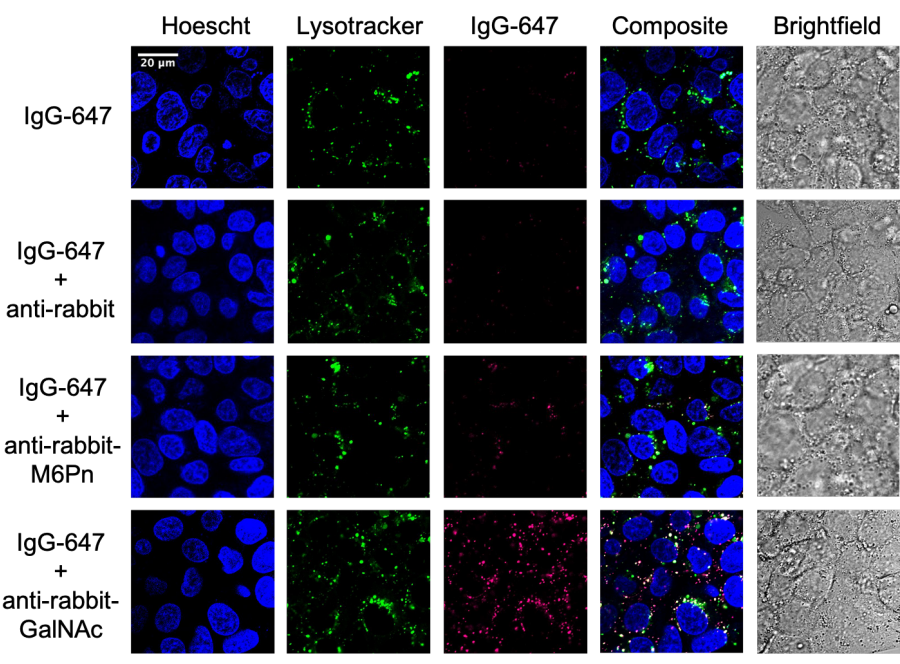

Fig. 1. LYTACs can hijack the asialoglycoprotein receptor (ASPGR) for targeted and cell-specific protein degradation. a, First-generation LYTACs co-opt the broadly expressed cation independent mannose 6-phosphate receptor (Cl-M6PR), whereas GalNAc-LYTACs target hepatocytes specifically. b, Synthesis of tri-GalNAc ligand for ASGPR-targeting. c, Synthesis of antibody-tri-GalNAc conjugates (GalNAc-LYTACs). Native gel electrophoresis of IgG, IgG-N 3 , and IgG-GalNAc. d, LYTAC-mediated internalization of anti-rabbit IgG-647 in HEPG2 cells. e, Mean fluorescence intensity (MFI) relative to the control (anti-rabbit lgG-647 only) for HEPG2 cells incubated at $37{ }^{\circ} \mathrm{C}$ for 1 
h with 50 nM anti-rabbit IgG-647 and 25 nM goat-anti-rabbit, goat-anti-rabbit-M6Pn, or goat-anti-rabbit-GalNAc. MFI determined by live cell flow cytometry; values are the average of three independent experiments $\pm S E M$. * $P<0.05$; ${ }^{* *} \mathrm{P}<0.01$; ${ }^{* *} \mathrm{P}<0.001$, determined by Student's two-tailed t-test. $\mathbf{f}$, Live-cell imaging of HEPG2 cells that were incubated at $37^{\circ} \mathrm{C}$ for $1 \mathrm{~h}$ with $50 \mathrm{nM}$ anti-rabbit IgG-647 and $25 \mathrm{nM}$ goat-anti-rabbit, goat-anti-rabbit-M6Pn, or goatanti-rabbit-GalNAc. 
a

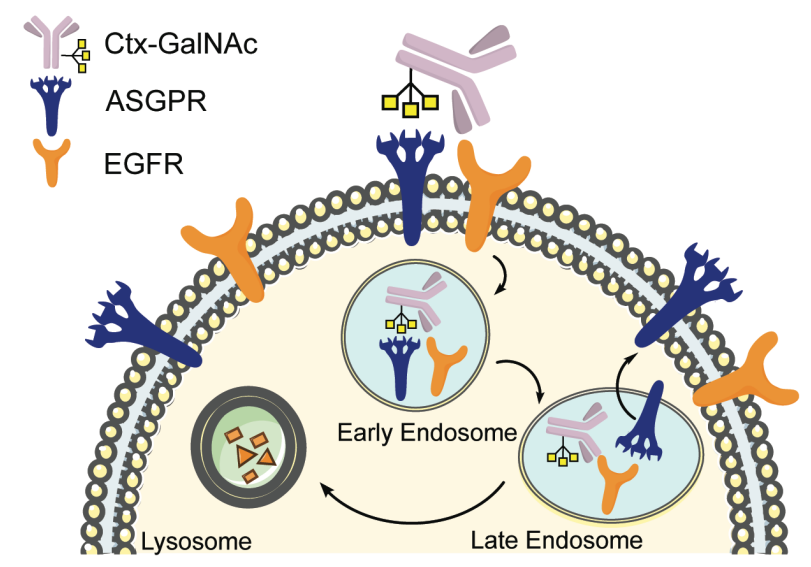

b
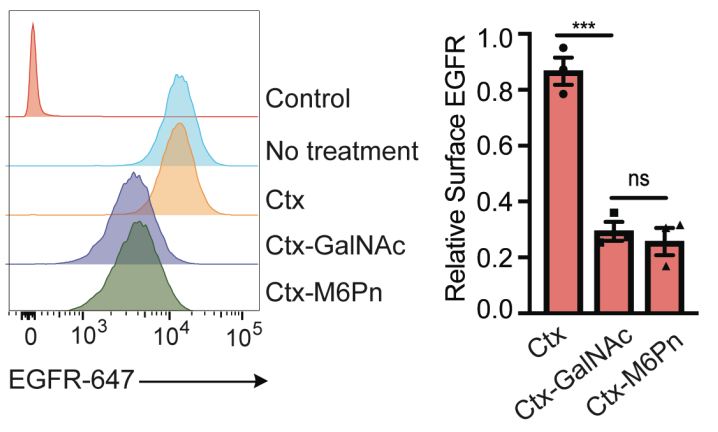

C
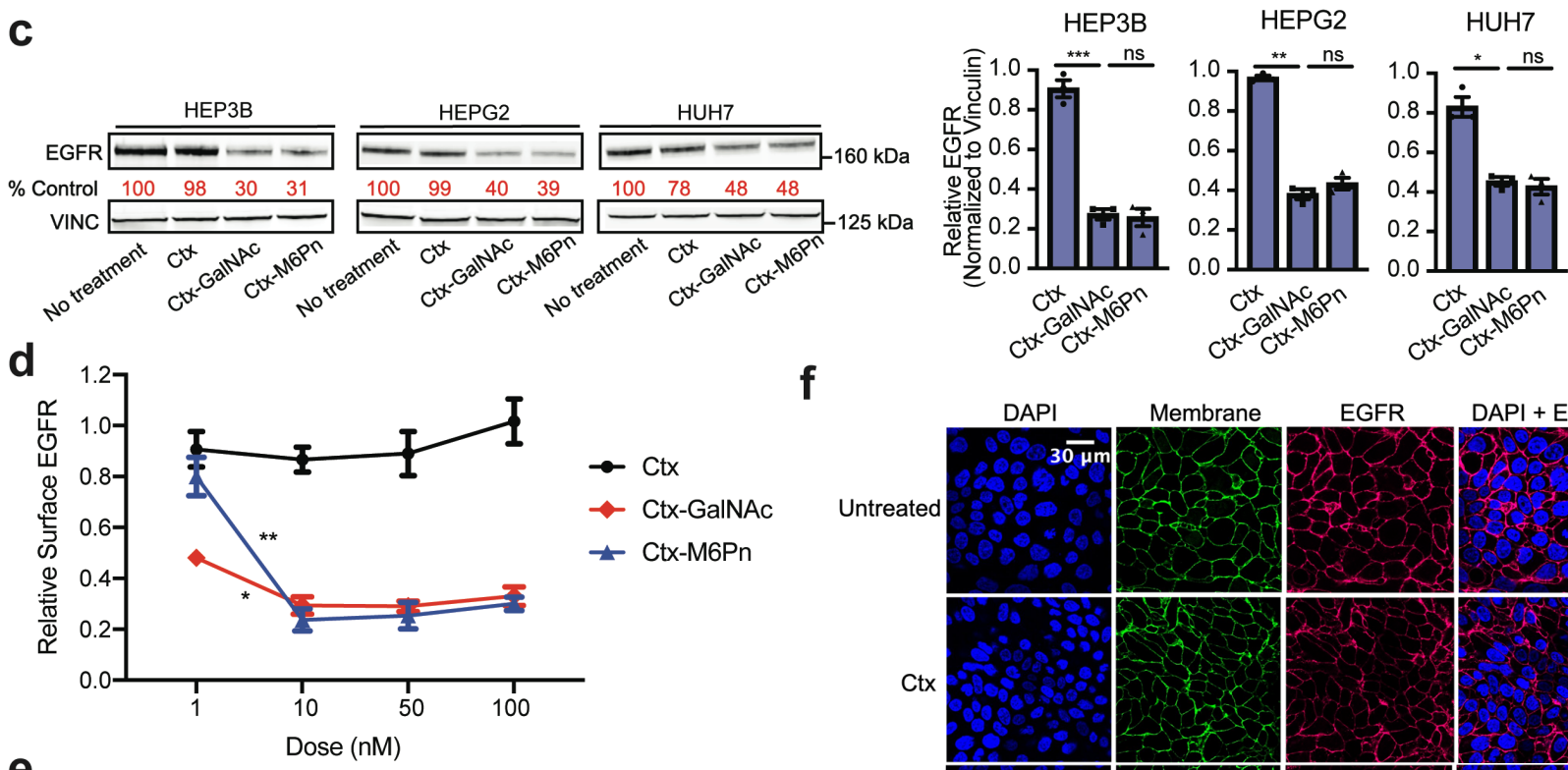

f

e
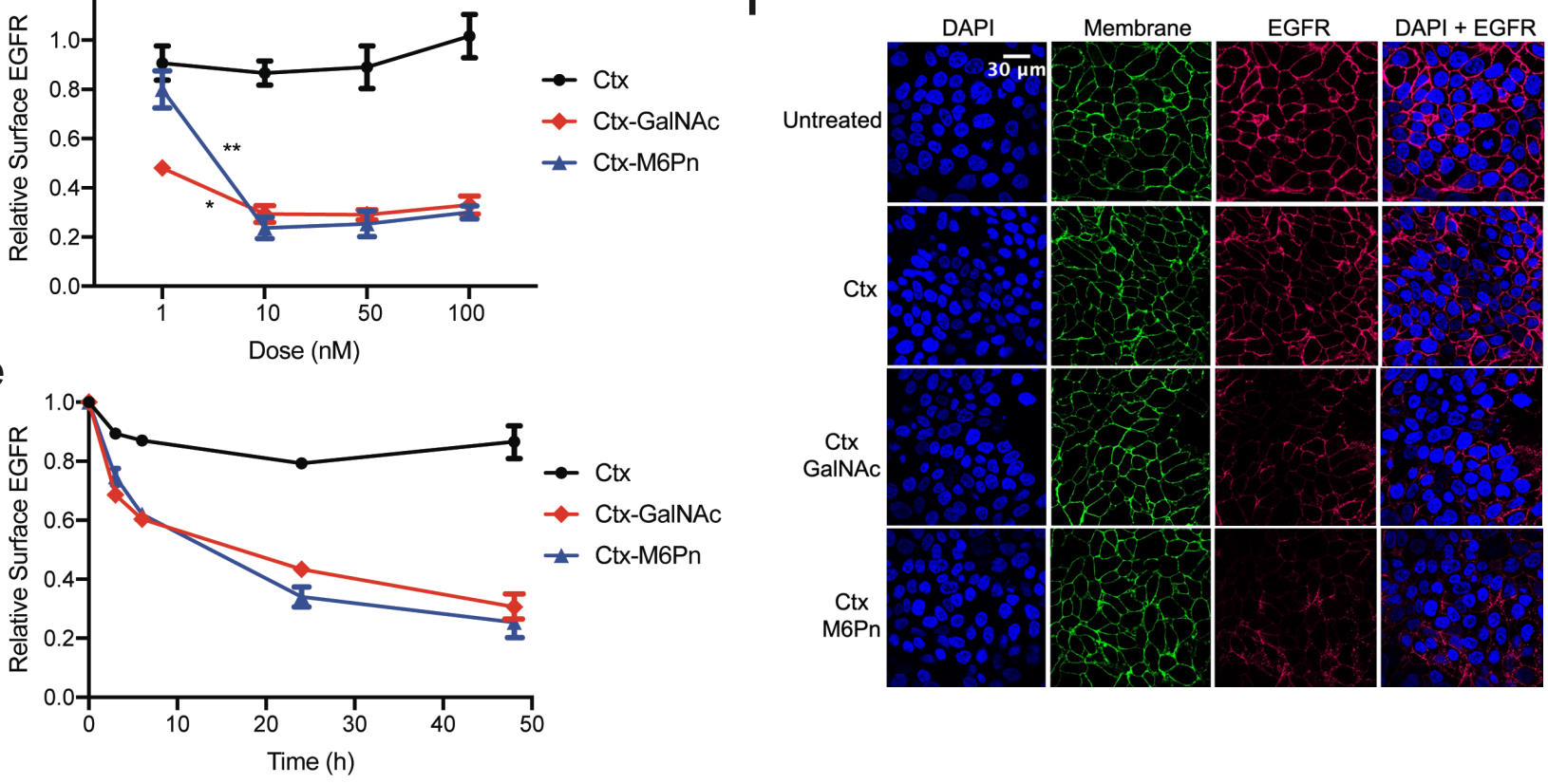

Fig. 2. GaINAC-LYTACs promote degradation of epidermal growth factor receptor (EGFR) in HCC cell lines. a, EGFR degradation mediated by cetuximab (Ctx)-GalNAc. b. Degradation of cell surface EGFR in HEP3B determined by live cell flow cytometry following $48 \mathrm{~h}$ of treatment with $10 \mathrm{nM}$ cetuximab or conjugates. c, Western blot analysis of total EGFR levels in HEP3B, HEPG2, and HUH7 after treat with $10 \mathrm{nM}$ cetuximab conjugates for $48 \mathrm{~h}$. d, Doseresponse curve for cell surface EGFR degradation in HEP3B incubated with $1 \mathrm{nM}, 10 \mathrm{nM}, 50 \mathrm{nM}, 100 \mathrm{nM}$ cetuximab conjugates for $48 \mathrm{~h}$. Relative surface expression of EGFR is determined by live cell flow cytometry and values are the average of three independent experiments \pm SEM. e, Time-course of degradation of cell surface EGFR in HEP3B incubated with $10 \mathrm{nM}$ cetuximab conjugates for $3,6,24$, and $48 \mathrm{~h}$. Relative surface expression of EGFR is determined by live cell flow cytometry and values are the average of three independent experiments \pm SEM. $\mathbf{f}$, Visualization of EGFR degradation in HEP3B cells by confocal microscopy after $10 \mathrm{nM}$ cetuximab conjugate treatments for $48 \mathrm{~h}$. ${ }^{*} \mathrm{P}<0.05 ;{ }^{* *} \mathrm{P}<0.01 ;{ }^{* * *} \mathrm{P}<0.001$, determined by Student's two-tailed t-tests. 
a

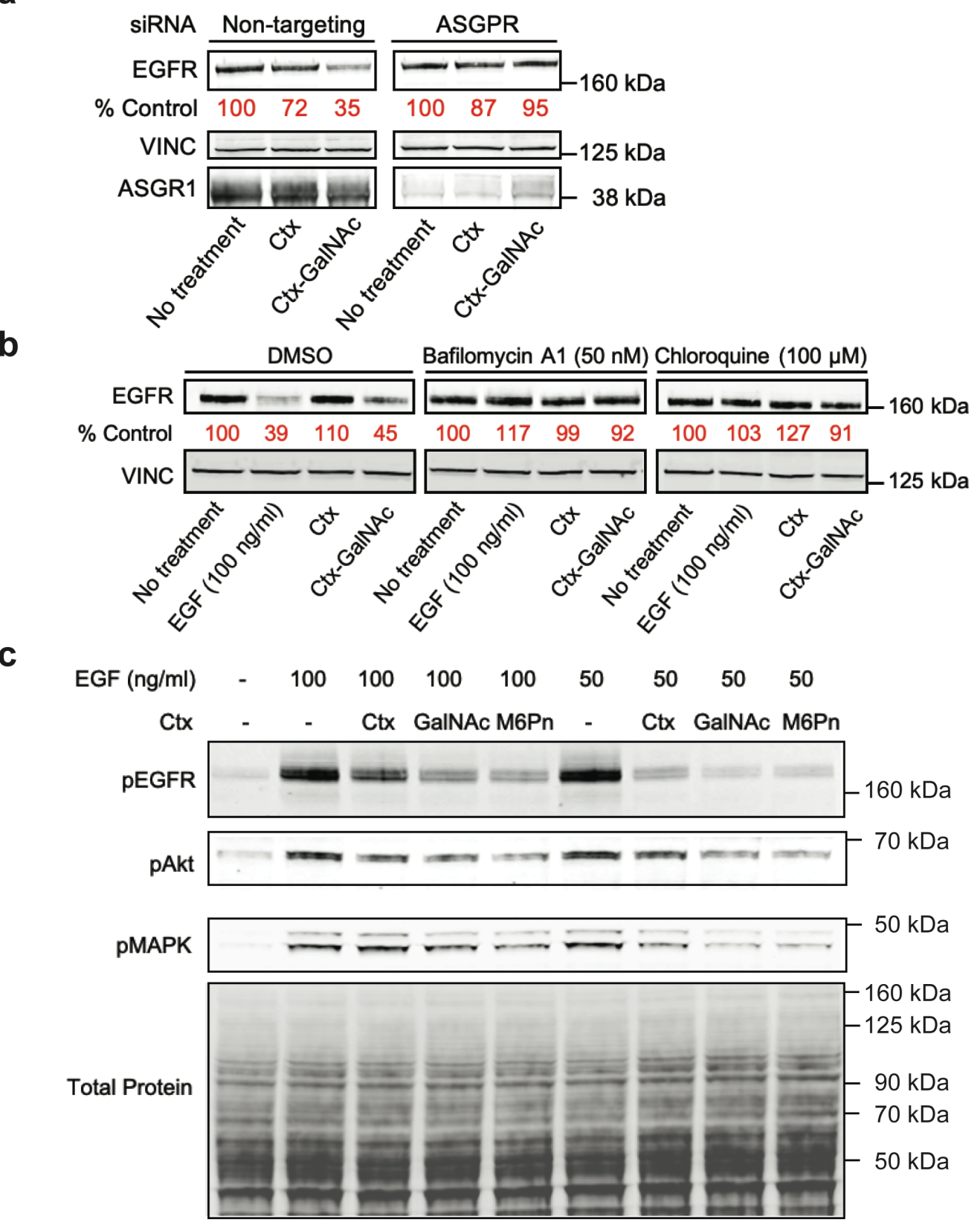

Fig 3. GaINAC-LYTACs operate via an endo-lysosomal mechanism and attenuate EGFR-driven signaling. a, Western blot of EGFR in HEP3B cells treated with $10 \mathrm{nM}$ cetuximab conjugates for $48 \mathrm{~h}$ following knockdown of ASGPR by siRNA. Non-targeting siRNA is included as a control. b. Western blot of EGFR degradation in HEP3B cells incubated with $10 \mathrm{nM}$ cetuximab conjugates and $50 \mathrm{nM}$ bafilomycin A1 or $10 \mu \mathrm{M}$ chloroquine for $24 \mathrm{~h}$. c, Western blot of pEGFR, pAkt, and pMAPK following incubation of $10 \mathrm{nM}$ cetuximab conjugates for $48 \mathrm{~h}$ then $1 \mathrm{~h}$ stimulation with $100 \mathrm{ng} / \mathrm{ml}$ or $50 \mathrm{ng} / \mathrm{ml}$ of EGF. 
a

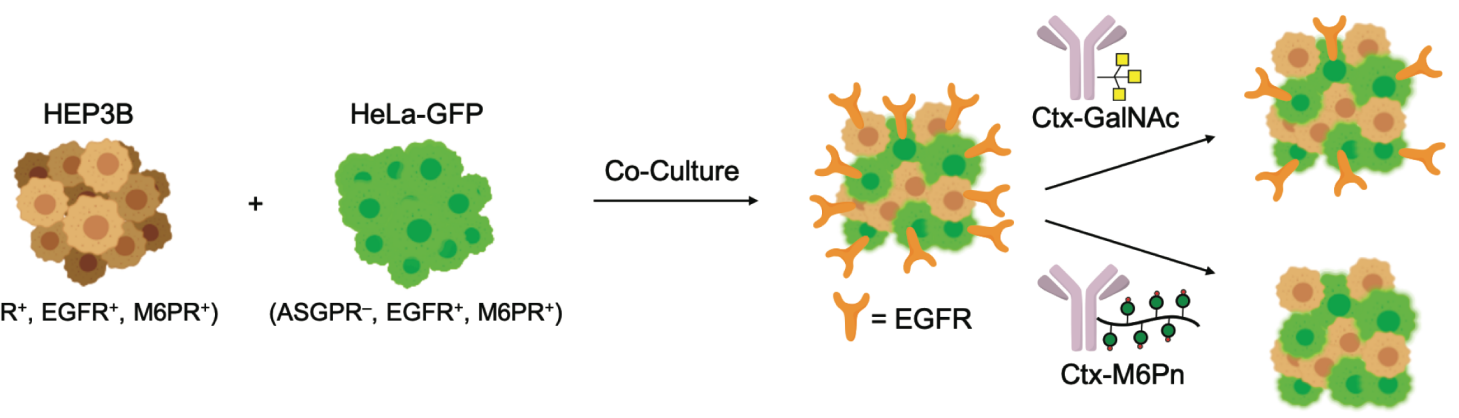

b

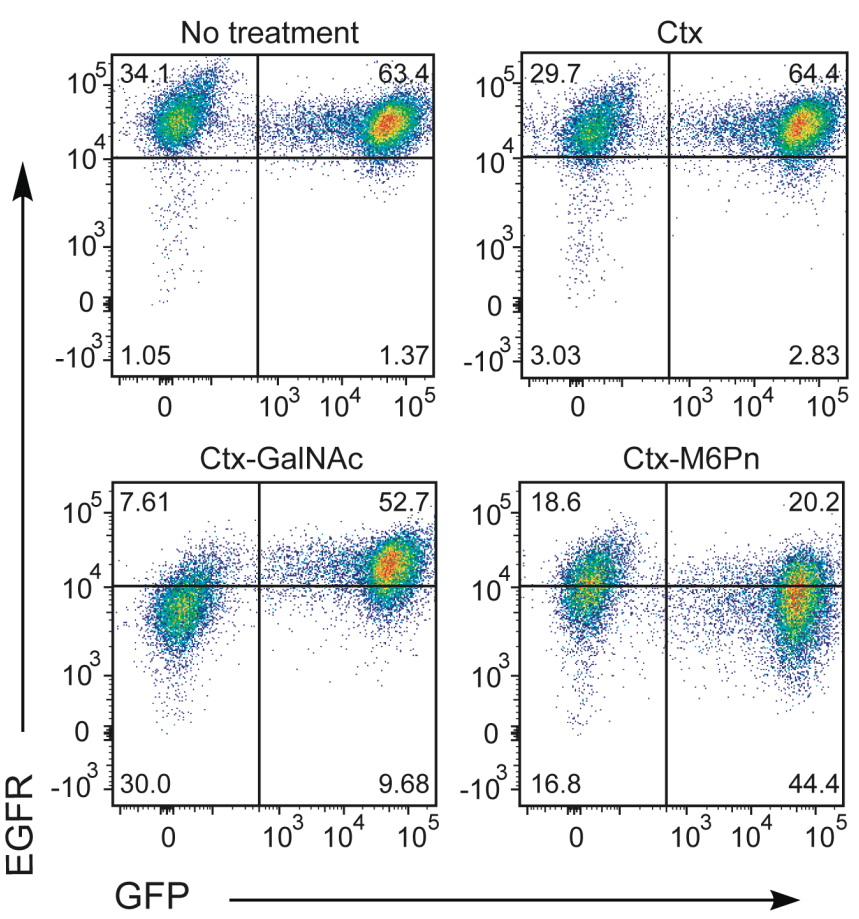

Fig 4. Ctx-GaINAc mediates selective degradation of EGFR on ASGPR expressing cells. a, HEP3B (ASGPR+, EGFR+, M6PR+) and HeLa-GFP (ASGPR-, EGFR+, M6PR+) were co-cultured and treated with cetuximab conjugates. Ctx-GalNAc degrades EGFR selectively in HEP3B cells. $\mathbf{b}$, Cell-surface EGFR levels in HEP3B cells and HeLa-GFP cells following co-culture and treatment with $50 \mathrm{nM}$ cetuximab or conjugates for $48 \mathrm{~h}$. Relative surface expression of EGFR was determined by live cell flow cytometry and values are the average of three independent experiments \pm SEM. ${ }^{*} P<0.05 ;{ }^{* *} P<0.01$, determined by Student's two-tailed t-test.

Figure B - GFP arrow for the flow, vertical arrow for EGFR 
a

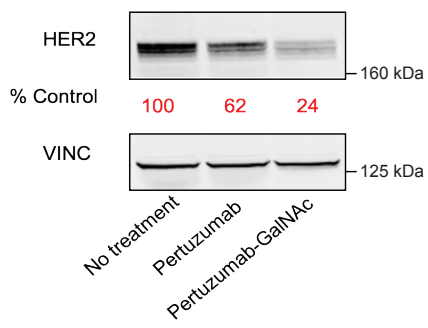

C

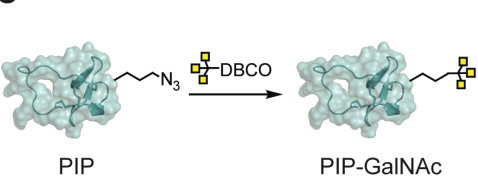

PIP

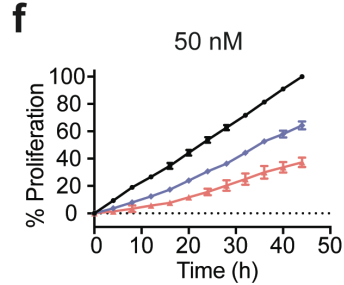

PIP-GaINAc b
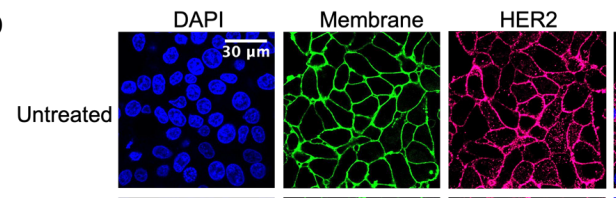

DAPI + HER2
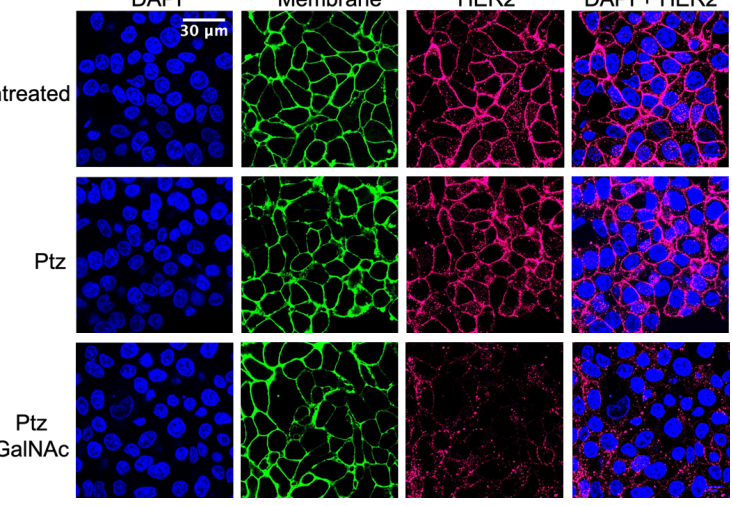

d

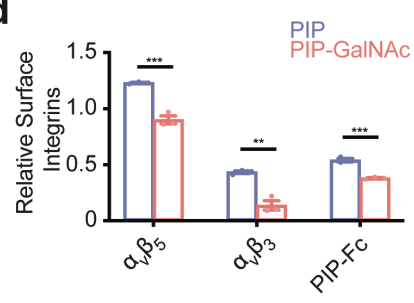

e

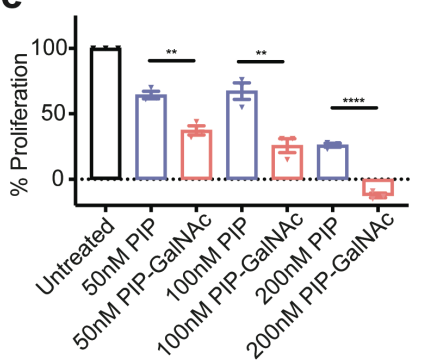

$\mathrm{g}$
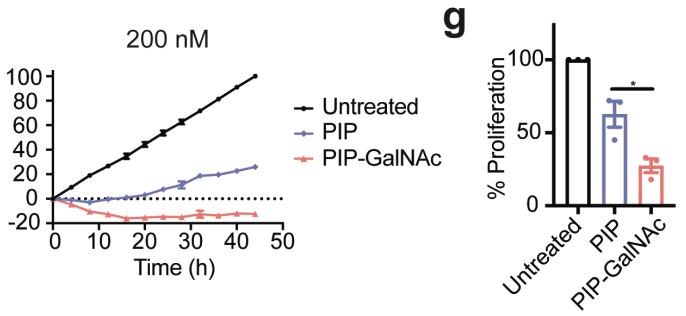

h
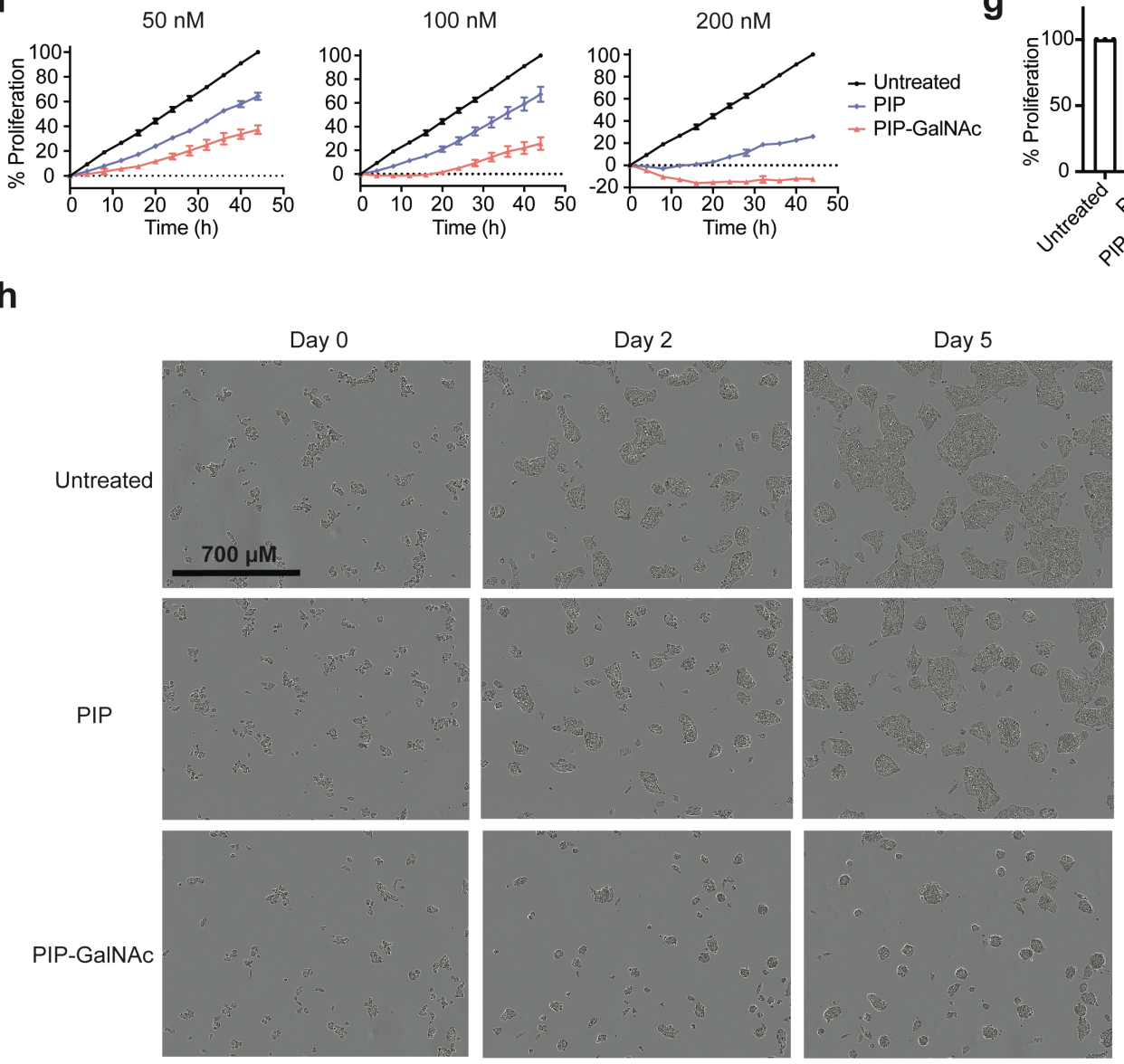

Fig. 5. GaINAC-LYTAC degrades membrane proteins HER2 and integrins and induces anti-proliferative effects in HEPG2 cells. a, Western blot of HER2 degradation in HEPG2 cells following incubation with $10 \mathrm{nM}$ pertuzumab 
(Ptz) or Ptz conjugates for 48 h. b, Visualization of HER2 degradation in HEPG2 cells by confocal microscopy after 10 $\mathrm{nM}$ pertuzumab conjugate treatments for 48 h. c, Synthesis of PIP-GalNAc. Tri-GalNAc-DBCO was conjugated to PIP, a knottin peptide that binds to multiple integrins. d, Degradation of cell surface integrins in HEPG2 determined by live cell flow cytometry following $44 \mathrm{~h}$ of treatment with $100 \mathrm{nM}$ PIP or PIP-GalNAc. PIP-Fc is a fusion of PIP to the Fc domain of mouse IgG2a, and measures the expression of surface integrins that PIP binds to. After treatment with PIP or PIP-GalNAc, cells were washed with EDTA to remove bound PIP, then stained with PIP-Fc. e, Percent proliferation of HEPG2 cells following $44 \mathrm{~h}$ of treatment with 50, 100, and $200 \mathrm{nM}$ PIP or PIP-GalNAc. Proliferation was quantified by phase confluence over time on IncuCyte. $f$, Time-course percent proliferation of HEPG2 cells during $44 \mathrm{~h}$ of treatment with 50, 100, and 200 nM PIP or PIP-GalNAc. g, Percent proliferation of HEPG2 cells following 5 days of treatment with 100 nM PIP or PIP-GalNAc. h, Live HEPG2 imaging by IncuCyte throughout 5 days after treatment with 100 nM PIP or PIP-GalNAc. Values are the average of three independent experiments $\pm \mathrm{SEM}$. ${ }^{*} \mathrm{P}<0.05 ;{ }^{* *} \mathrm{P}<0.01 ;{ }^{* * *} \mathrm{P}<$ $0.001,{ }^{* * * *} P<0.0001$ determined by Student's two-tailed t-test. 
a

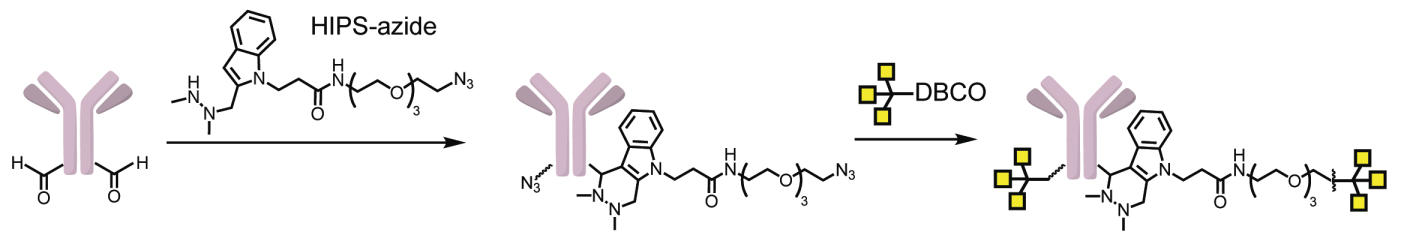

b

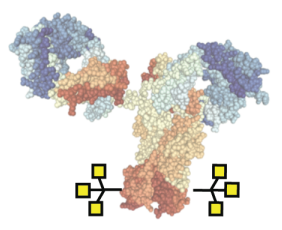

C-terminus

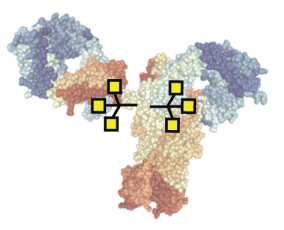

Hinge

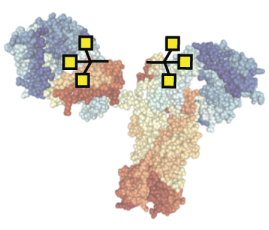

$\mathrm{CH} 1$ Heavy Chain
C

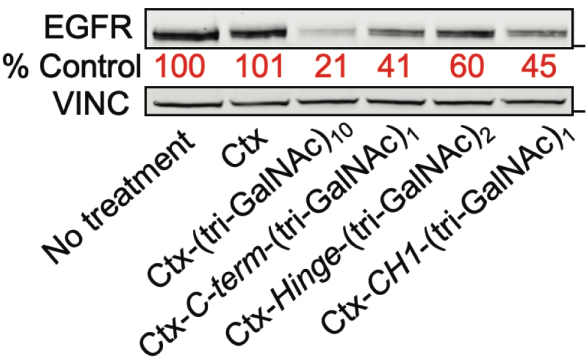

d

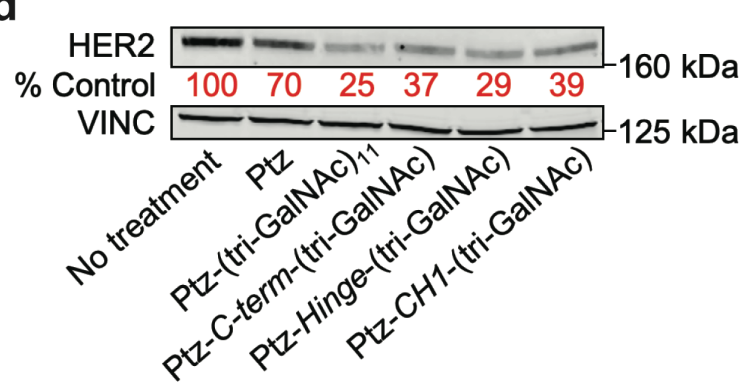

e

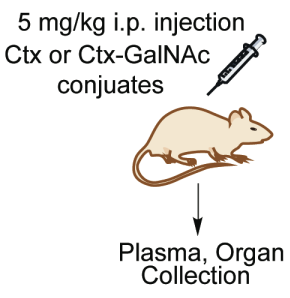

f

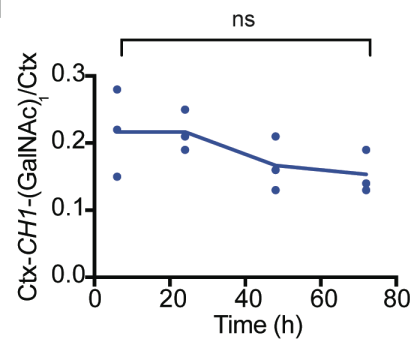

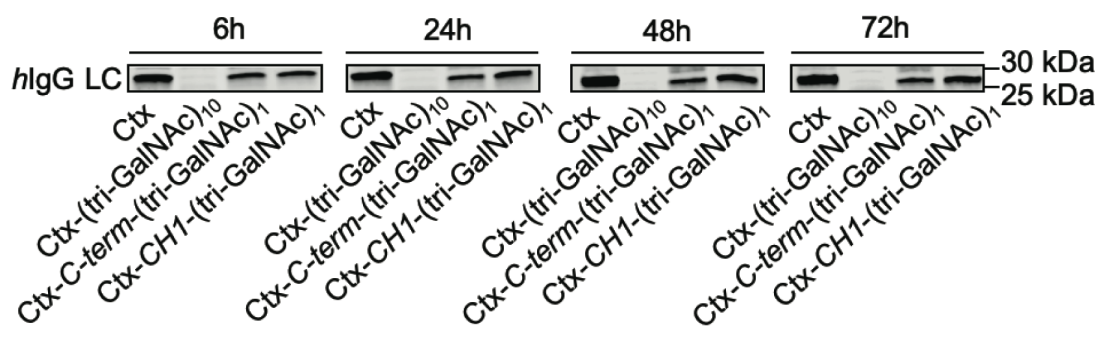

g

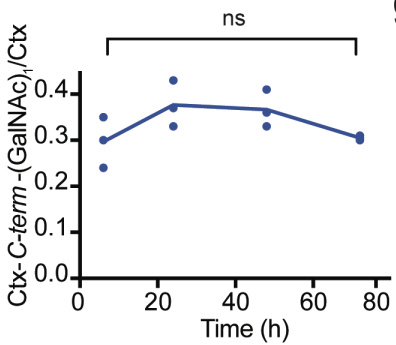

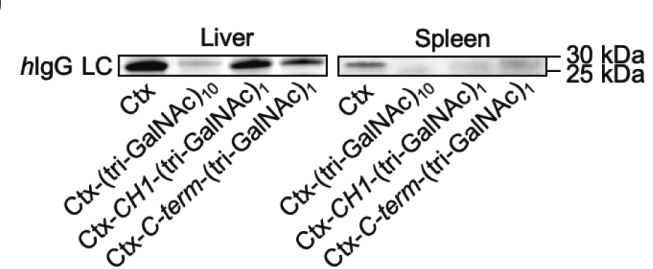

Fig. 6. Site-specific conjugation improves pharmacokinetics of antibody-based GalNAc-LYTACs. a, Site-specific conjugation of Ctx using the SMARTag technology ${ }^{42}$. Ctx was expressed with formylglycine residue in 3 different positions, and was reacted with HIPS-azide ${ }^{43,44}$ followed by tri-GalNAc-DBCO. $\mathbf{b}$, Site-specific conjugation of antibody at the $\mathrm{CH} 1$ domain, hinge, and C-terminus of the antibody. c, Western blot of EGFR degradation in HEP3B after treatments with $10 \mathrm{nM}$ site-specific cetuximab conjugates for $48 \mathrm{~h}$. d, Western blot of HER2 degradation in HEPG2 cells after treatments with $100 \mathrm{nM}$ site specific pertuzumab conjugates for $48 \mathrm{~h}$. e, In vivo pharmacokinetic study of GalNAc LYTACs. Representative human-lgG light chain western blot of plasma following $5 \mathrm{mg} / \mathrm{kg}$ i.p. injection of Ctx, Ctx-(GalNAc) ${ }_{10}, \mathrm{Ctx}-\mathrm{CH} 1-(\mathrm{GalNAc})_{1}$, Ctx-C-term-(GalNAc) $)_{1}$ Plasma was collected 6, 24, 48, and $72 \mathrm{~h}$ post injection. f, Quantification of e representing the ratio of site specific Ctx conjugates over unmodified Ctx. Values are the average of three separate mice \pm SEM. g, Representative human-lgG light chain blot of liver and spleen $72 \mathrm{~h}$ after Ctx and Ctx conjugate injections. 